\title{
Temperature Changes in Central Asia from 1979 to 2011 Based on Multiple Datasets*
}

\author{
ZENGYUN HU \\ State Key Laboratory of Desert and Oasis Ecology, Xinjiang Institute of Ecology and Geography, Chinese Academy \\ of Sciences, and College of Mathematics and System Sciences, Xinjiang University, Urumqi, China \\ CHI ZHANG \\ School of Resources Environment Science and Engineering, Hubei University of Science and Technology, Hubei, \\ and State Key Laboratory of Desert and Oasis Ecology, Xinjiang Institute of Ecology and Geography, \\ Chinese Academy of Sciences, Urumqi, China

\section{QI HU} \\ School of Natural Resources and Department of Earth and Atmospheric Sciences, University \\ of Nebraska-Lincoln, Lincoln, Nebraska \\ HANQIN TIAN \\ International Center for Climate and Global Change Research, and School of Forestry and Wildlife Sciences, \\ Auburn University, Auburn, Alabama
}

(Manuscript received 28 January 2013, in final form 27 September 2013)

\begin{abstract}
The arid and semiarid region in central Asia is sensitive and vulnerable to climate variations. However, the sparse and highly unevenly distributed meteorological stations in the region provide limited data for understanding of the region's climate variations. In this study, the near-surface air temperature change in central Asia from 1979 to 2011 was examined using observations from 81 meteorological stations, three local observation validated reanalysis datasets of relatively high spatial resolutions, and the Climate Research Unit (CRU) dataset. Major results suggested that the three reanalysis datasets match well with most of the local climate records, especially in the low-lying plain areas. The consensus of the multiple datasets showed significant regional surface air temperature increases of $0.36^{\circ}-0.42^{\circ} \mathrm{C} \mathrm{decade}^{-1}$ in the past 33 years. No significant contributions from declining irrigation and urbanization to temperature change were found. The rate is larger in recent years than in the early years in the study period. Additionally, unlike in many regions in the world, the temperature in winter showed no increase in central Asia in the last three decades, a noticeable departure from the global trend in the twentieth century. The largest increase in surface temperature was occurring in the spring season. Analyses further showed a warming center in the middle of the central Asian states and weakened temperature variability along the northwest-southeast temperature gradient from the northern Kazakhstan to southern Xinjiang. The reanalysis datasets also showed significant negative correlations between temperature increase rate and elevation in this complex terrain region.
\end{abstract}

\footnotetext{
* Supplemental information related to this paper is available at the Journals Online website: http://dx.doi.org/10.1175/JCLI-D-1300064.s1.

Corresponding author address: Dr. Chi Zhang, School of Resources Environment Science and Engineering, Hubei University of Science and Technology, Xianning, Hubei, China.

E-mail: zc@ms.xjb.ac.cn
}

\section{Introduction}

The arid and semiarid region in central Asia covers $5 \times 10^{6} \mathrm{~km}^{2}$, including Kazakhstan, Kyrgyzstan, Tajikistan, Turkmenistan, Uzbekistan, and Xinjiang province in northwest China. The region is especially sensitive and vulnerable to climate change (UNDP 2005; Parry et al. 2007). Rising air temperatures increase the surface evapotranspiration, stimulate substantial glacial retreats,

DOI: 10.1175/JCLI-D-13-00064.1 
and exacerbate water shortage in the region (UNDP 2005; Siegfried et al. 2012; Sorg et al. 2012). Because of the critical dependence on climate of the water resources, ecosystems, and societies in this massive inland region, it is crucial to understand its climate variation and change in order to support sustainable development policies. Our review has found few studies that examined climate variation in central Asia (e.g., Houghton et al. 2001; Lioubimtseva et al. 2005; Lioubimtseva and Cole 2006; Lioubimtseva and Henebry 2009), especially its temperature variation. The Intergovernmental Panel on Climate Change (IPCC; Houghton et al. 2001) reported that the region's averaged near-surface air temperature rose by $1^{\circ}-2^{\circ} \mathrm{C}$ during the twentieth century. However, the report provided no specific information about its temporal (e.g., the time of abrupt temperature changes) or spatial (e.g., areas of substantial temperature rise or fall) variations. Meanwhile, large uncertainties have been noticed existing in these previous studies, arising from either using observational records from a few meteorological stations (e.g., Kharlamova and Revyakin 2006; Mamtimin et al. 2011) or using a single spatially interpolated dataset of the Climate Research Unit (CRU) time series from New et al. (1999, 2000) and Mitchell and Jones (2005) in the region. As pointed out by Lioubimtseva and Cole (2006), the spatial interpolation or extrapolation was particularly prone to errors in this region of very complex terrains with rather sparse and highly skewed spatially distributed meteorological stations. In comparison with other regions, the limited weather stations in central Asia are clustered in and around the oases. Moreover, long-term climatic observations are rare (Lioubimtseva and Cole 2006). Most stations outside China stopped functioning in the 1990s after the dissolution of the former Soviet Union (Chub 2000), losing continuation of data for analysis of regional climate variations in the recent decades (Schiemann et al. 2008). These problems in data pose severe challenges for the study of climate in central Asia and limit our understanding of the spatial and temporal variations in temperatures in the region.

The National Centers for Environmental Prediction (NCEP)-National Center for Atmospheric Research (NCAR) reanalysis dataset (Kalnay et al. 1996) provided an alternative data source and helped overcome some of the data issues. While the reanalysis data have been widely used in regional climate studies (e.g., Marshall 2002; Blender and Fraedrich 2003; Bromwich and Fogt 2004; Bordi et al. 2006; Bromwich et al. 2007; Song and Zhang 2007; Grotjahn 2008; Dessler and Davis 2010; Bao and Zhang 2012), the data have rarely been used in climate studies for central Asia except for a few studies on the region's precipitation (e.g., Schiemann et al. 2008), partially because the spatial resolution of the dataset $\left(2.5^{\circ} \times 2.5^{\circ}\right.$ of latitude and longitude $)$ was considered too coarse to describe important details in regional climate in central Asia.

In the last few years, a new generation of reanalysis datasets has been developed with improved accuracy and spatial resolution $\left[\leq\left(0.75^{\circ} \times 0.75^{\circ}\right)\right.$ of latitude and longitude]. These new datasets include the NCEP Climate Forecast System Reanalysis (CFSR; Saha et al. 2010), European Centre for Medium-Range Weather Forecasts (ECMWF) Interim Re-Analysis (ERA-Interim; Dee et al. 2011), and Modern-Era Retrospective Analysis for Research and Applications (MERRA; Rienecker et al. 2011). These data could be suitable for regional climate studies in central Asia. However, as cautioned by the data producers, few evaluations have been made so far and the suitability and accuracy of these global datasets for regional studies are not yet fully understood (https:// climatedataguide.ucar.edu/reanalysis/climate-forecastsystem-reanalysis-cfsr). Because of the differences in the models and methods used in these reanalysis projects these datasets may, for example, describe nearsurface air temperatures (Pitman and Perkins 2009). Thus, before using them their suitability or accuracy to describe the regional climate features needs to be evaluated against available field observations (Ma et al. 2008).

In this study, we first examine the accuracy of the three relatively high spatial resolution datasets, CFSR, ERA-Interim, and MERRA, in describing the regional temperature variations in central Asia by comparing the reanalysis data with observations from stations in the region. After the evaluation these datasets are used to examine temperature variations in central Asia for the period from 1979 to 2011.

There are three major questions to be addressed in this study. Was there a warming trend in central Asian climate in recent decades? If there was, how does it compare to the temperature changes in the mid- and early-twentieth century, and how does it compare with temperature changes in other regions in the Eurasian continent? Were there changes in seasonal temperature variation in central Asia and which season experienced the strongest temperature change? Were there significant differences in temperature change among different subregions of central Asia and how does the temperature change rate vary with elevation?

\section{Study area, data, and methodologies}

\section{a. Study area}

Our study area consists of Xinjiang Uygur Autonomous Region, China (Xinjiang), and five central Asian states (CAS): Kazakhstan, Kyrgyzstan, Tajikistan, Turkmenistan, 

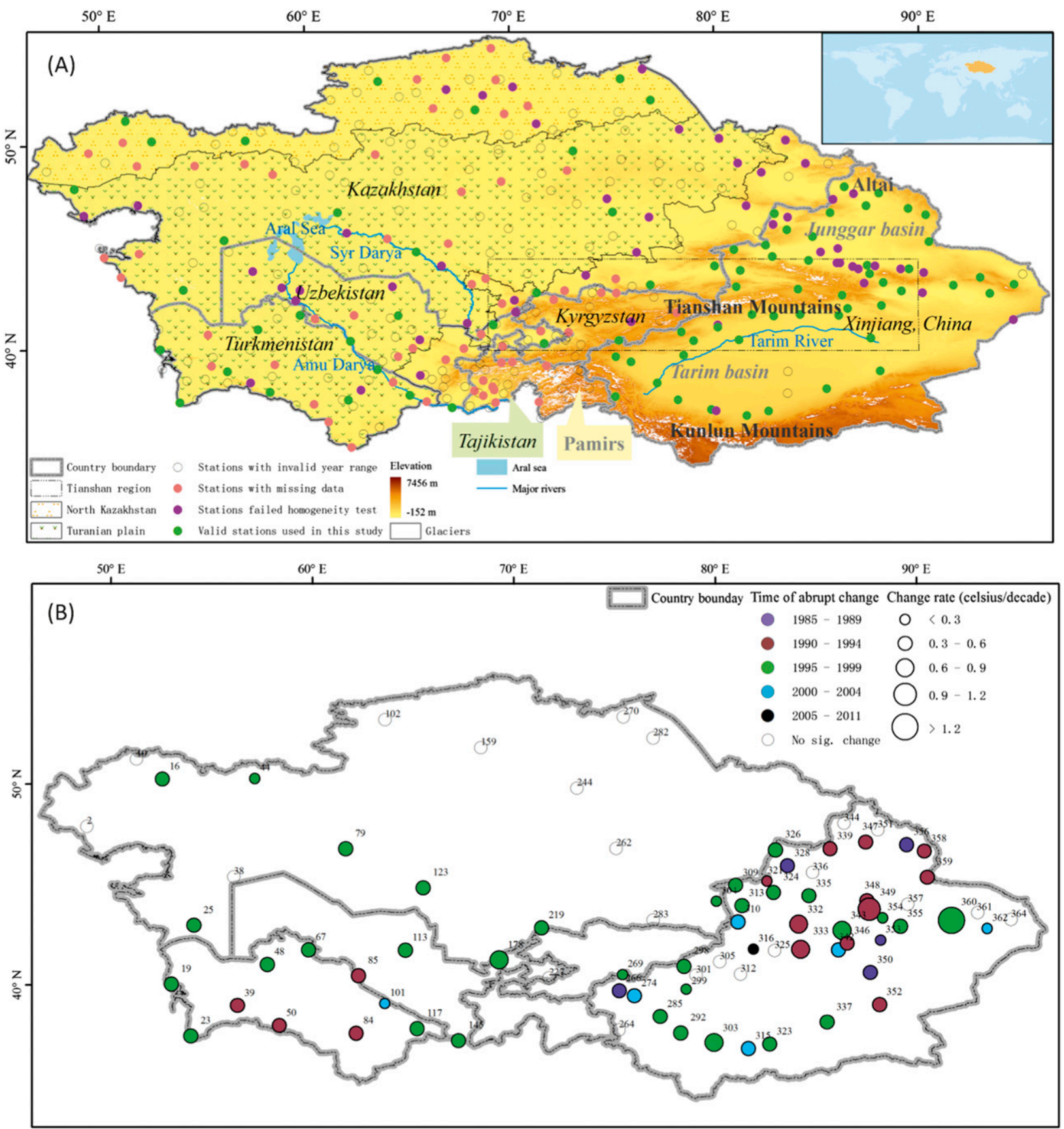

FIG. 1. The study area and distribution of meteorological stations. (a) The location, elevation, country boundary, subregions, and major water and orographic features in central Asia. The dashed-line rectangle delineates the Tian Shan region $\left(40^{\circ}-44.5^{\circ} \mathrm{N}, 69^{\circ}-\right.$ $\left.90^{\circ} \mathrm{E}\right)$. Climate stations are represented by circles filled with different colors, indicating different data quality. The country boundary and major rivers were drawn with the Environmental Systems Research Institute, Inc. (ESRI) Basemap Services (http://www.esri. com/software/arcgis/arcgis-online-map-and-geoservices/map-services). (b) Distribution of the meteorological stations and their temperature change from 1979 to 2011. The identification (ID) numbers of the stations are labeled (station descriptions are found in Table S1 in the supplementary material). The size of each circle is in proportion to the rate of change. An open circle indicates no significant change at the station. A filled circle indicates significant temperature change, and the color of the filling indicates the turning point (in a time span of $5 \mathrm{yr}$ ) of temperature change in 1979-2011 according to the M-K test. 
and Uzbekistan (Fig. 1a). We will refer this region as central Asia. There have been discrepancies and discussions about the usage of the term "central Asia." In some publications, central Asia refers to western China and Mongolia (Le Houerou 2005); in others, it refers to the five CAS in the former Soviet Union (e.g., Mayhew et al. 2004). Our definition agrees with Goudie (2002)'s description, in which central Asia consists of two parts separated by high mountains, including the Pamirs, the Tian Shan Mountains, Kunlun Mountains, and Altai Mountains (Fig. 1a): "To the west lie the deserts of the former Soviet Union and to the east are the deserts of China" (Goudie 2002).

According to the topography and climate characteristics, the CAS are usually divided into three climatic subregions: the northern Kazakhstan region in the north, the Turanian plain in the central and southeast, and the mountainous region in the southwest [definitions of these climatic subregions also can be found in Schiemann et al. (2008) and Small et al. (1999)]. In addition, Xinjiang consists of two climatic subregions: the northern Xinjiang and the southern Xinjiang. The former consists of the Junggar basin and the Altai Mountains to its north and the northern slope of the Tian Shan Mountains to its south and west. The latter consists of the Tarim basin and the southern slope of the Tian Shan Mountains to its north and the Kunlun Mountains and Pamir Plateau to its south and west (Fig. 1a). To investigate the relationship between elevation and temperature change, we further outline the Tian Shan region $\left(40^{\circ}-44.5^{\circ} \mathrm{N}, 69^{\circ}-90^{\circ} \mathrm{E}\right)$ (Fig. 1a) according to Chen (2012).

\section{b. Data}

Daily observational records of near-surface $(2 \mathrm{~m}$ above the ground) air temperatures from 365 meteorological stations in the study region were collected in this study. Among them, 295 stations are in the five central Asian states, and their temperature records were obtained from the National Climatic Data Center (NCDC) of the U.S. National Oceanic and Atmospheric Administration (NOAA). The remaining 70 stations are in Xinjiang, China, and their records were obtained from the National Meteorological Center of China Meteorological Administration and from Xinjiang Meteorological Agency. The data history of these stations is shown in Table 1 . These data are referred to as OBS in the following sections.

Among the reanalysis data, we used the monthly CRU time series 3.1 (TS3.1) dataset (New et al. 1999; Mitchell and Jones 2005) from 1901 to 2009. We also used the NCEP CFSR, ERA-Interim, and MERRA datasets. Some details of these reanalysis datasets are provided in
Table 1. These datasets were first examined by comparisons with observations from the ground stations for their accuracy in describing the near-surface air temperature, and then to aid the analysis of spatial variations in the near-surface temperature. For the analyses that require elevation information (see below), the 30-arc-s resolution digital elevation data (GTOPO30; downloaded from http://eros.usgs.gov) were resampled to match the spatial resolution of each reanalysis dataset. The elevation at each reanalysis data grid was calculated as the mean of the digital elevation data within that grid. To assess the potential impacts of climate change on the dryland ecosystems and water resources in central Asia, we further evaluated changes in temperature in vegetated and glacial areas in central Asia. The glacial and vegetated areas were determined with the 300-m resolution European Space Agency global land cover dataset (GlobCover 2009; Arino et al. 2010), which has been evaluated and used for environmental studies in the study region (Chen et al. 2013). The "glacier area" in the GlobCover 2009 includes permanent snow and glacier. Boundaries of northern Kazakhstan and the Turanian plain in the CAS region were digitized based on the maps provided by Small et al. (1999) and Schiemann et al. (2008).

\section{c. Methodologies}

Quality control of the OBS involves three steps. 1) Stations whose climate records did not cover the analysis period were excluded. 2) Stations with missing observations for more than 5 consecutive days or with $20 \%$ observation missing in any 30 -day period were excluded. Otherwise, the missing values in the climate records were filled with 30-day running means. 3) Stations that failed to pass the standard normal homogeneity test were excluded (Alexandersson 1986). This homogenization test aims to preserve the climatic signal and eliminate or reduce the effects on nonclimatic factors from such changes in instrumentations, observing practices, and station locations (Aguilar et al. 2003; Li et al. 2004; DeGaetano 2006). For example, among the 365 meteorological stations under study, only 191 cover the period between 1979 and 2011, among which 59 have too many missing values to pass the quality control (step 2). Of the remaining 132 stations, only 81 stations passed the homogeneity test and were used in climate change analysis for the period of 1979-2011 (Fig. 1a). The longer the study period, the fewer number of stations passed quality control. Compared to the period of 1979-2011, only 62 stations are qualified for climate change analyses for the period of 1960-2011 (Table 1).

The three reanalysis data products are evaluated by comparing their temperatures against the OBS at or 
near the reanalysis grid points for the 1980s, 1990s, and $2000 s+(2000-11)$. For each meteorological station, its closest grid in a reanalysis dataset is identified. Then, the temperature of the reanalysis data at that grid is adjusted according to the lapse rate and the elevation difference between the grid and the station. This elevation difference was calculated using the GTOPO30 developed by the U.S. Geological Survey (USGS; http:// eros.usgs.gov). Annual and seasonal temperature lapse rates $\left[{ }^{\circ} \mathrm{C}(100 \mathrm{~m})^{-1}\right]$ in central Asia were calculated based on the 1979-2011 mean temperature in the Tian Shan region $\left(40^{\circ}-44.5^{\circ} \mathrm{N}, 69^{\circ}-90^{\circ} \mathrm{E}\right)$ (Fig. 1a) (see Table $\mathrm{S} 2$ in the supplementary material). The seasonal mean lapse rates were then linearly interpolated to derive the daily lapse rate, which was used for the temperature adjustment.

Following Ma et al. (2008) and You et al. (2010), the absolute errors (AE) or bias, two-tailed Pearson correlation coefficients (CC), mean absolute errors (MAE), and root-mean-square error (RMSE) were calculated to measure various aspects of the differences between the observed air temperatures and those from the three reanalysis datasets. The reanalysis products were evaluated separately for mountainous and plain areas. The definition of mountainous area by the United $\mathrm{Na}$ tions Environment Programme (UNEP) was used; that is, a mountainous area should have elevation $>2500 \mathrm{~m}$, or between 1500 and $2500 \mathrm{~m}$ and with a slope $>2^{\circ}$, or between 1000 and $1500 \mathrm{~m}$ and with a slope $>5^{\circ}$ or local elevation range $>300 \mathrm{~m}$ (Blyth et al. 2002). Information of topography was derived from the USGS GTOPO30 elevation dataset. For each grid in the USGS GTOPO30 dataset, the local elevation range was derived from a $5 \times 5 \mathrm{~km}^{2}$ buffer around the grid. Areas outside of the mountainous area were treated as plain areas.

Temporal variations of the temperature were compared between the OBS and the CRU, and between the OBS and each of the three reanalysis datasets. In these comparisons, each meteorological station or each grid in the spatial datasets was treated as a sample point, and the mean values for the study region were analyzed and compared. Trends of temperature variation were evaluated using linear trend fit and the nonparametric Mann-Kendall method (or M-K test) (Mann 1945; Kendall 1948). A trend was considered statistically significant when it is at the $95 \%$ confidence level. The M-K test also was used to detect the time of significant or abrupt climate changes. Temperature changes in the four seasons, spring [March-May (MAM)], summer [June-August (JJA)], fall [September-November (SON)], and winter [December-February (DJF)], as well as the annual (ANN) change were examined. Furthermore, we analyzed the OBS and the CRU data to examine the temperature variation and trend for the past five decades (1961-2011) and also from 1901 to 2009. These long-term variations in temperature were compared to the variation from 1979 to 2011 to put the recent changes in context. The method used to study temperature change at the turn of the twenty-first century was by comparing and contrasting the differences (DIF) of the change from the 1980s to the 1990s and the change from the 1990 s to 2000 s + (i.e., 2000-11):

$$
\begin{aligned}
\mathrm{DIF}_{1990 \mathrm{~s}-1980 \mathrm{~s}} & =T_{1990 \mathrm{~s}}-T_{1980 \mathrm{~s}} \\
\mathrm{DIF}_{2000 \mathrm{~s}+-1990 \mathrm{~s}} & =T_{2000 \mathrm{~s}+}-T_{1990 \mathrm{~s}} .
\end{aligned}
$$

In the above, $T\left({ }^{\circ} \mathrm{C}\right)$ is a decadal mean temperature.

To compare the spatial pattern of surface temperature change derived from the CRU, CFSR, ERA-Interim, and MERRA datasets, we applied empirical orthogonal function (EOF) analyses (Lorenz 1956) to their annual temperature anomalies (from the average of 1979-2011). EOF analysis finds a set of orthogonal variables to describe the observed variance in the data, whereby largescale variability will be shown in the low-order EOFs while the higher-order EOFs contain low-amplitude spatially incoherent noise. The EOF method can identify the dominant spatial pattern of the variation in temperature and also produces its index time series, the principal component (PC), which explains the magnitude of the variation of each EOF mode of the temperature. Following North et al. (1982), a significance test is applied to distinguish the physical signal from the noise in the EOF.

Dependence of the change in near-surface temperature on elevation is examined for the Tian Shan mountainous region, which is the major mountain area in central Asia (Fig. 1a). Although the Pamirs in Tajikistan are as important for the Amu Darya as the Tian Shan Mountains are for the Syr Darya and other rivers, they are not investigated because no valid stations in the Pamirs are available for this analysis (Fig. 1b). Pepin and Lundquist (2008) suggested that a reliable analysis of the relationship between temperature change and elevation should be based on observations from meteorological stations in the mountain summit or freely draining slopes. To identify such meteorological stations, we overlay the location map of the stations on the topographic maps (relief map and slope map) derived from the USGS GTOPO30 dataset and the high-resolution (about 1-10 m) remote sensing maps retrieved from http://www.google.com/earth (last visited by the authors on 4 July 2013). A visual check showed only three stations meeting the criteria of Pepin 


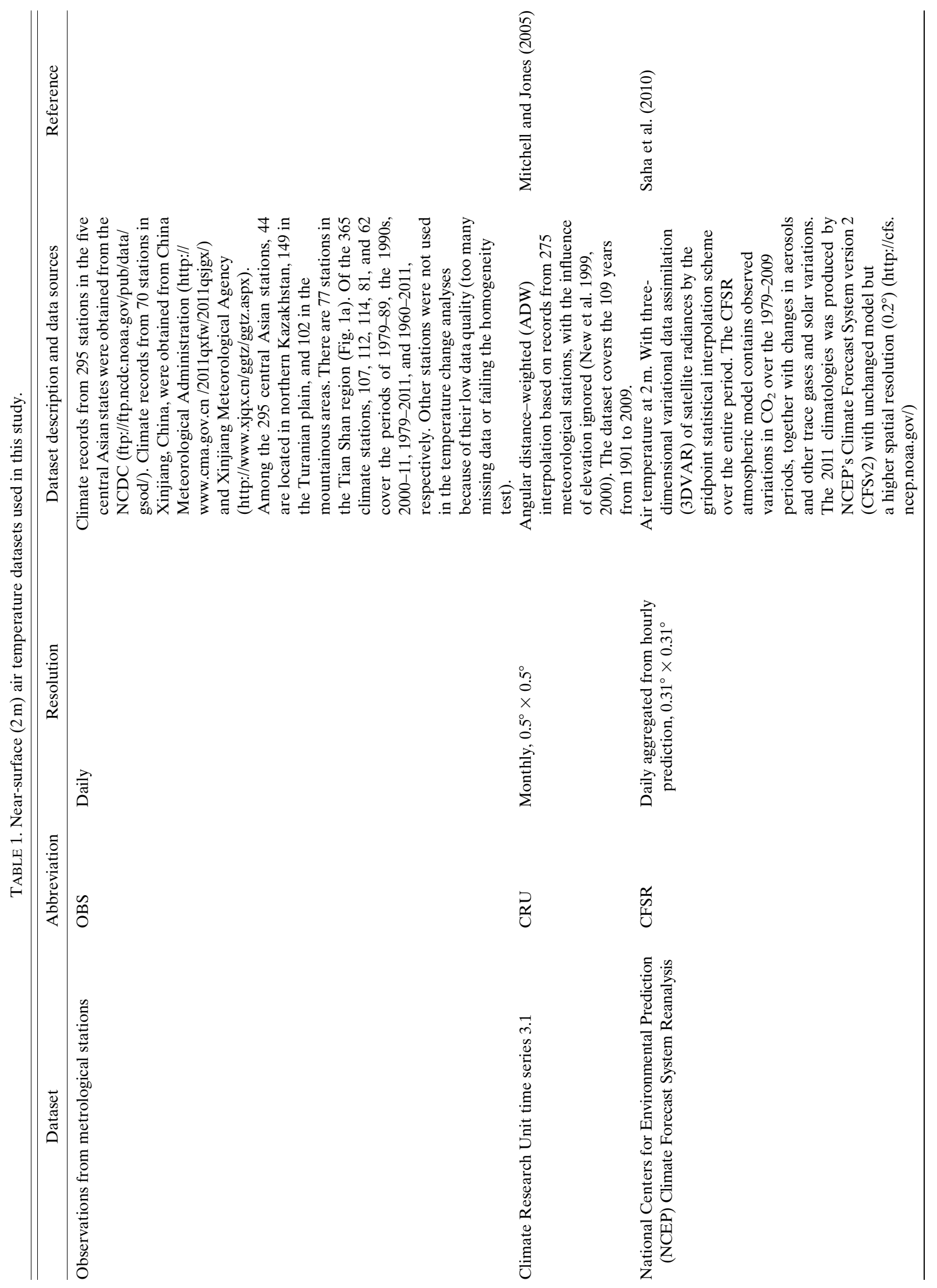


and Lundquist (2008): Turgart (station ID 269), Balgantai (station ID 343), and Akqi (station ID 298). Station information is found in Table S1 of the supplementary material. Because of the lack of qualified stations, in this study only the three reanalysis datasets are used in analyzing the elevation effect on temperature change.

Since these reanalysis datasets have different spatial resolutions, we also resampled the CFSR and MERRA datasets to match the coarser resolution $\left(0.75^{\circ} \times 0.75^{\circ}\right.$ in latitude and longitude) in the ERA-Interim dataset to examine, by comparing the results to the original datasets, whether the analysis results could be influenced by scaling or spatial resolution.

\section{Results and analyses}

\section{a. Evaluating the reanalysis datasets with climate records}

We used the observational data to evaluate the reanalysis datasets for their accuracy in describing the near-surface temperature in central Asia. In this evaluation, we first collected data from 365 meteorological stations in our study region. Of the 365 stations, there are 107, 112, and 114 with continuous surface temperature records in the 1980s, 1990s, and 2000s + , respectively. The increasing number of stations in those decades is attributable to new stations added to the network. Although new stations were added, the addition could not compensate for the damages done by stopping observations at some historical stations in the early 1990s after the former Soviet Union disintegrated. There are only 81 and 62 stations that have continuous climate observations in the periods of 1979-2011 and 1960-2011, respectively. The spatial distribution of the stations is shown in Fig. 1a. It should be noted that the long-term stations (covering the 1979-2011 period), from which the climate trend is derived, were not evenly distributed in central Asia (Fig. 1b). Many areas, such as the Pamirs, the deserts in the middle of the Tarim and Junggar basins, and the northern part of the Turanian plain have very low station density. Such poor station coverage makes it difficult to use the station data to investigate climate change in those areas. The gaps in station observations can, however, be filled with information provided by spatially explicit reanalysis products that utilize model simulation outputs. To assure that the model simulations are reasonable in describing the climate in the regions it is necessary to first evaluate the reanalysis datasets using the quality-controlled station records (i.e., OBS). 
TABLE 2. Evaluating three reanalysis products using annual mean temperature recorded by meteorological stations in central Asia.

\begin{tabular}{|c|c|c|c|c|c|c|}
\hline \multirow[b]{2}{*}{ Period } & \multirow[b]{2}{*}{ Region } & \multirow[b]{2}{*}{ Reanalysis product } & \multicolumn{4}{|c|}{ Statistics } \\
\hline & & & $\mathrm{AE}\left({ }^{\circ} \mathrm{C}\right)$ & $\mathrm{CC}$ & $\operatorname{MAE}\left({ }^{\circ} \mathrm{C}\right)$ & $\operatorname{RMSE}\left({ }^{\circ} \mathrm{C}\right)$ \\
\hline \multirow[t]{9}{*}{$1980 \mathrm{~s}$} & Plain area (74 stations) & CFSR & 0.4 & 0.93 & 1.27 & 1.73 \\
\hline & & ERA-Interim & 0.25 & 0.92 & 1.19 & 1.9 \\
\hline & & MERRA & 1.79 & 0.92 & 2.08 & 2.71 \\
\hline & Mountain area (33 stations) & CFSR & -1.19 & 0.83 & 2.54 & 3.44 \\
\hline & & ERA-Interim & -2.12 & 0.68 & 3.47 & 4.62 \\
\hline & & MERRA & 1.59 & 0.85 & 3.22 & 4.03 \\
\hline & All areas (107 stations) & CFSR & -0.09 & 0.89 & 1.66 & 2.37 \\
\hline & & ERA-Interim & -0.48 & 0.84 & 1.9 & 2.99 \\
\hline & & MERRA & 1.73 & 0.89 & 2.43 & 3.16 \\
\hline \multirow[t]{9}{*}{$1990 \mathrm{~s}$} & Plain area (80 stations) & CFSR & 0.37 & 0.95 & 1.18 & 1.65 \\
\hline & & ERA-Interim & 0.11 & 0.93 & 1.2 & 1.89 \\
\hline & & MERRA & 1.72 & 0.92 & 2.07 & 2.68 \\
\hline & Mountain area (32 stations) & CFSR & -1.63 & 0.78 & 2.85 & 3.84 \\
\hline & & ERA-Interim & -2.43 & 0.61 & 3.62 & 4.80 \\
\hline & & MERRA & 1.35 & 0.79 & 3.23 & 4.02 \\
\hline & All areas (112 stations) & CFSR & -0.21 & 0.89 & 1.66 & 2.46 \\
\hline & & ERA-Interim & -0.61 & 0.85 & 1.89 & 3.00 \\
\hline & & MERRA & 1.62 & 0.89 & 2.4 & 3.11 \\
\hline \multirow[t]{9}{*}{$2000 \mathrm{~s}$} & Plain area (81 stations) & CFSR & 0.66 & 0.88 & 1.78 & 2.42 \\
\hline & & ERA-Interim & 0.16 & 0.85 & 1.99 & 2.75 \\
\hline & & MERRA & 1.97 & 0.85 & 2.69 & 3.47 \\
\hline & Mountain area (33 stations) & CFSR & -2.05 & 0.75 & 3.17 & 4.15 \\
\hline & & ERA-Interim & -2.72 & 0.6 & 3.82 & 5.1 \\
\hline & & MERRA & 0.18 & 0.69 & 3.43 & 4.46 \\
\hline & All areas (114 stations) & CFSR & -0.13 & 0.84 & 2.18 & 3.0 \\
\hline & & ERA-Interim & -0.67 & 0.78 & 2.52 & 3.57 \\
\hline & & MERRA & 1.45 & 0.81 & 2.91 & 3.76 \\
\hline \multirow[t]{9}{*}{ 1979-2011 average } & Plain area & CFSR & 0.48 & 0.92 & 1.41 & 1.93 \\
\hline & & ERA-Interim & 0.17 & 0.90 & 1.46 & 2.18 \\
\hline & & MERRA & 1.83 & 0.90 & 2.28 & 2.95 \\
\hline & Mountain area & CFSR & -1.62 & 0.79 & 2.85 & 3.81 \\
\hline & & ERA-Interim & -2.42 & 0.63 & 3.64 & 4.84 \\
\hline & & MERRA & 1.04 & 0.78 & 3.29 & 4.17 \\
\hline & All areas & CFSR & -0.14 & 0.87 & 1.83 & 2.61 \\
\hline & & ERA-Interim & -0.59 & 0.82 & 2.10 & 3.19 \\
\hline & & MERRA & 1.60 & 0.86 & 2.58 & 3.34 \\
\hline
\end{tabular}

Comparisons between the observed and reanalysis results of variations in near-surface air temperature show rather encouraging results: no significant differences in the annual and seasonal temperatures between the OBS and each of the three reanalysis datasets. As shown in Table 2, the surface temperatures in CFSR, ERA-Interim, and MERRA are significantly correlated with the OBS, with high correlation coefficients of 0.82 0.87. Compared to the OBS the average absolute error ranges from $-0.59^{\circ} \mathrm{C}$ for ERA-Interim to $1.6^{\circ} \mathrm{C}$ for MERRA. As also expected, all three reanalysis datasets show closer match with the OBS in the plains region (with CC of 0.90-0.92) than in mountainous areas (with CC of 0.63-0.79) (Table 2). The CC between the OBS and the three reanalysis datasets decreases slightly from 0.87 in the $1980 \mathrm{~s}$ and $1990 \mathrm{~s}$ to 0.81 in the $2000 \mathrm{~s}+$. These statistics indicate that the three reanalysis datasets can faithfully describe the temperatures and their variations in central Asia. In particular, the CSFR had the lowest AE, MAE, and RSME and highest CC among the three reanalysis datasets. Noticeably, CSFR also has the highest spatial resolution among all the three datasets (Table 1).

\section{b. Temporal variation in surface temperature based on multiple datasets}

The OBS, the CRU, and the three reanalysis datasets all show that central Asia has experienced a significant rise in surface temperatures from 1979-2011. Most areas in our study region, about $75 \%-90 \%$ according to linear least squares fitting and $60 \%-85 \%$ according to the M-K test, have experienced a significant (at the $95 \%$ confidence level) increase in annual mean temperatures in the period from 1980 to 2011 (Figs. 2a and 2b). Areas experiencing 
(A)

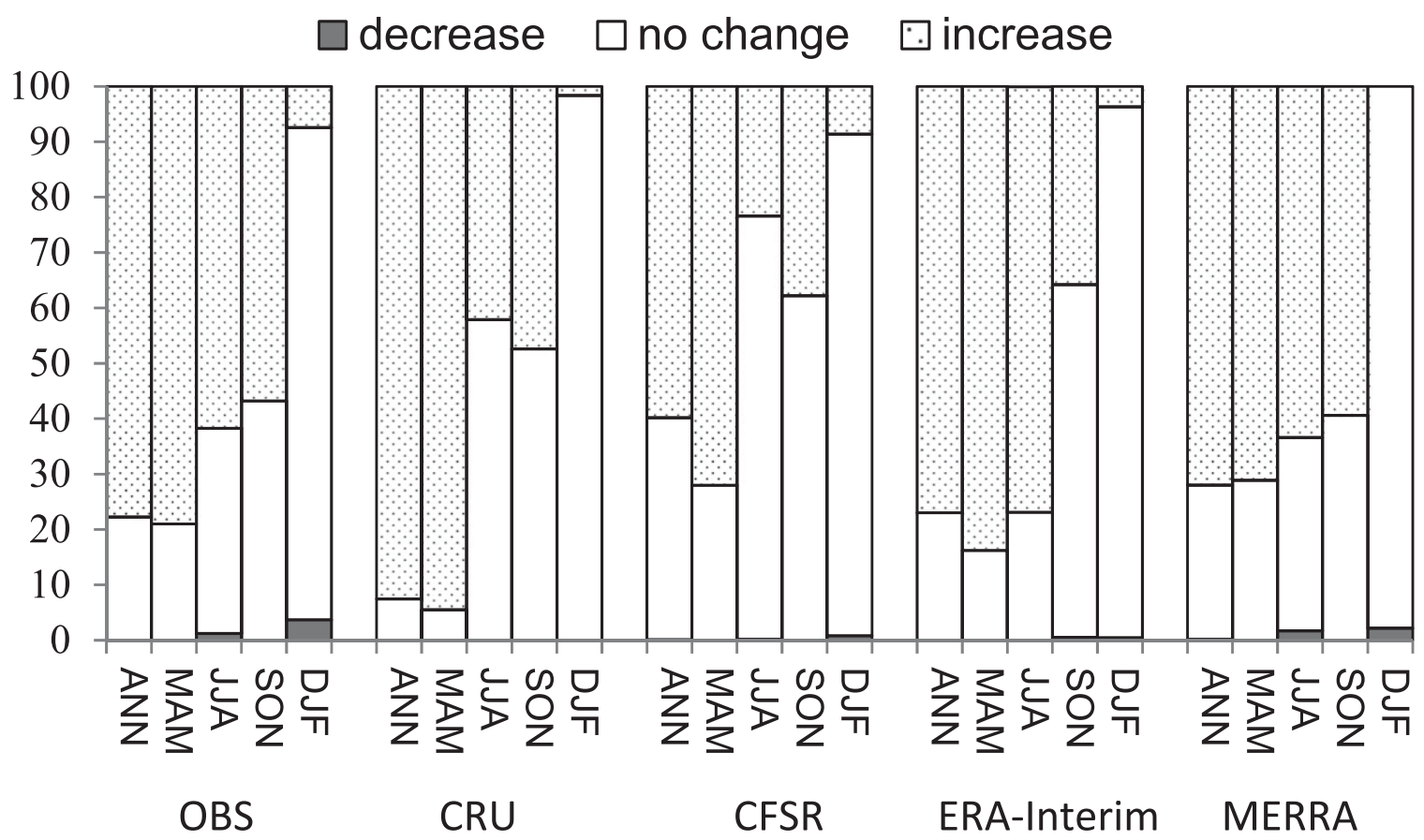

(B)

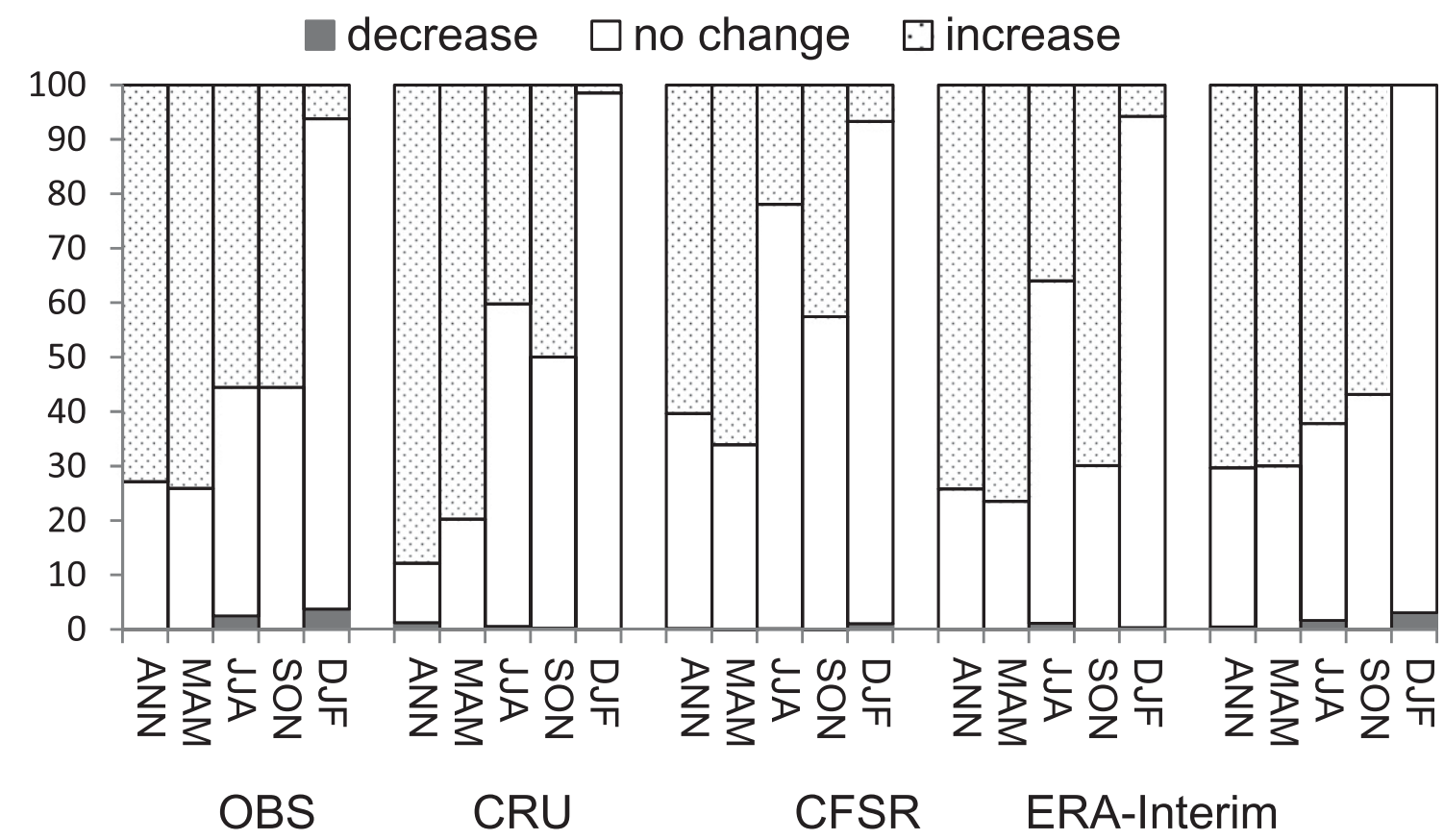

FIG. 2. Percentage of stations and study area (according to the CRU, CFSR, ERA-Interim, and MERRA datasets) showing no change (white) or significant (at the 95\% confidence level) warming (stippled) or cooling (gray) in surface temperature during 1979-2011. Results in are derived based on (a) linear trend fit and (b) the M-K test. Along the abscissa, ANN indicates annual, MAM spring, JJA summer, SON fall, and DJF winter.

cooling are rare. Results from linear fitting analysis show that the region's annual mean temperatures have increased at an average rate of $0.39^{\circ} \mathrm{C} \mathrm{decade}^{-1}$ (ranging from $0.36^{\circ}-0.42^{\circ} \mathrm{C}$ ecade $^{-1}$ ) from 1979 to 2011 (Figs. 3 and 4a). This rate is higher than the average warming rates of $0.30^{\circ}$ and $0.15^{\circ} \mathrm{C}$ decade $^{-1}$ in the last 5 decades (19602011) and 11 decades (1901-2009), respectively, based on the OBS and CRU datasets (Figs. 3b,c and 4a), as 
(A) Temperature change of OBS during 1979-2011

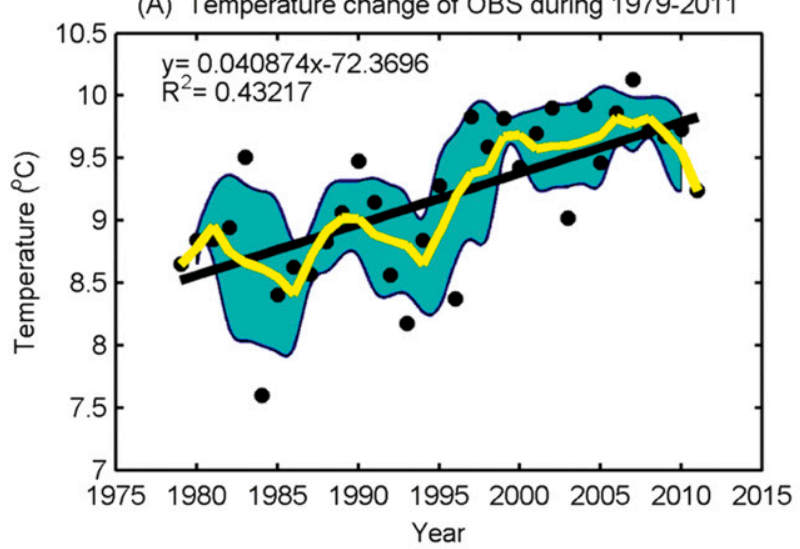

(C) Temperature change of CRU during 1901-2009

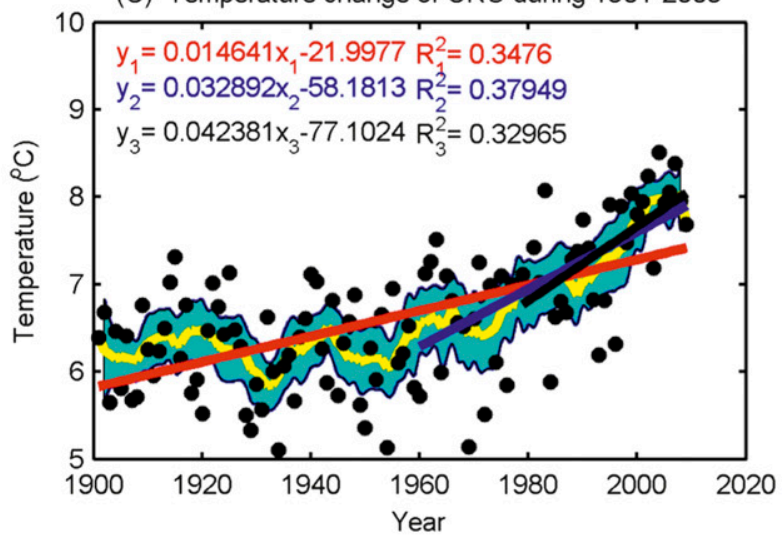

(E) Temperature change of ERA-Interim during 1979-2011

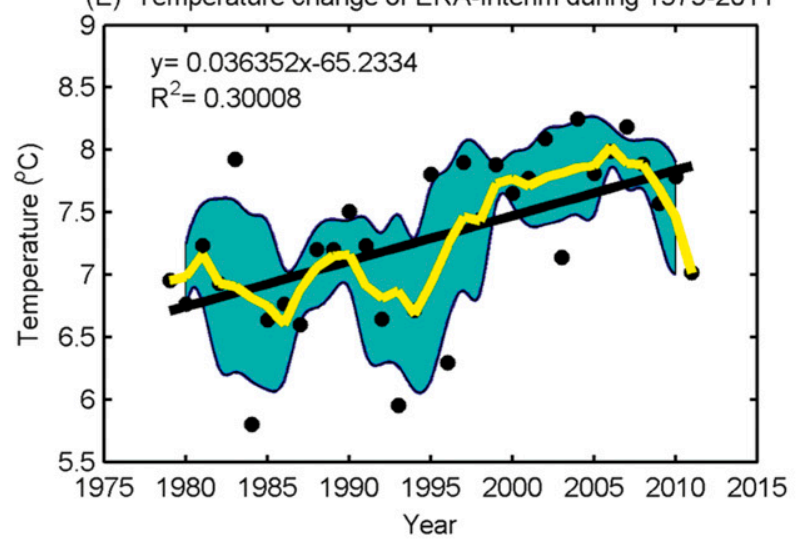

$95 \%$ confidence interval

5-years or 11-years moving average

Annual mean
(B) Temperature change of OBS during 1960-2011

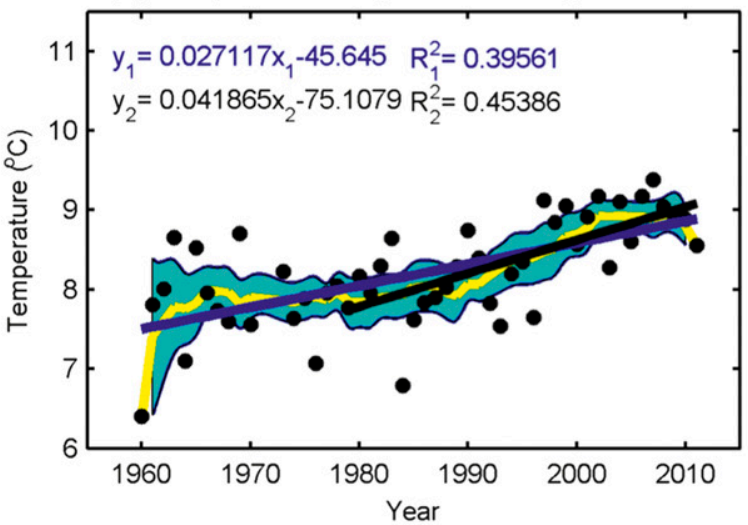

(D) Temperature change of CFSR during 1979-2011

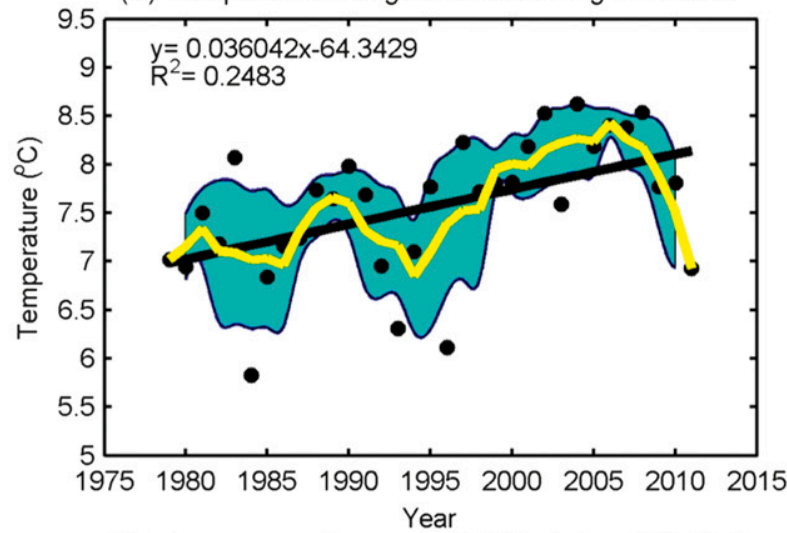

(F) Temperature change of MERRA during 1979-2011

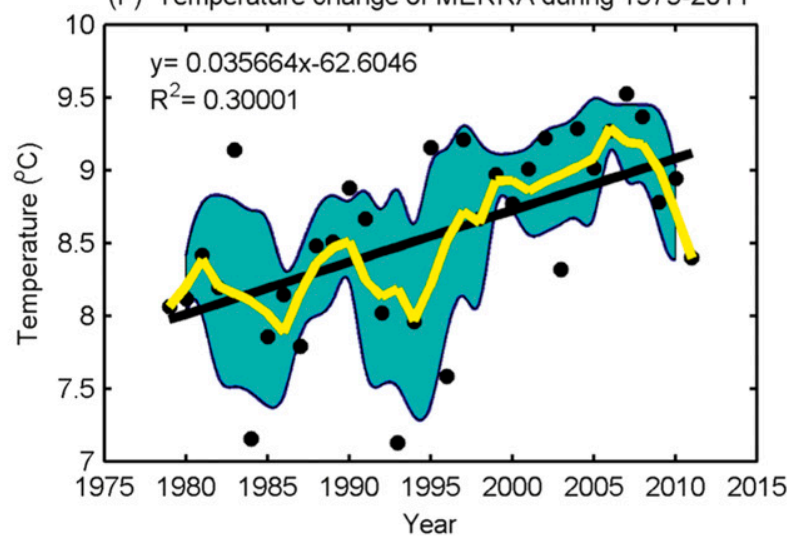

Trend $1(1901-2009)$

Trend $2(1960-2011)$

Trend 3 (1979-2011)

FIG. 3. Trends of temperature change: (a) from 1979 to 2011 based on observational records from 81 meteorological stations; (b) for 19792011 and 1960-2011 revealed by records from 62 meteorological stations; (c) for 1901-2009, 1960-2009, and 1979-2009 revealed by the CRU dataset; (d) for 1979-2011 revealed by the CFSR reanalysis dataset; (e) for 1979-2011 revealed by the ERA-Interim reanalysis dataset; and (f) for 1979-2011 revealed by the MERRA reanalysis dataset. In each panel, annual mean temperatures are shown by the dots along with a linear fit to the data to show the trend in temperature variation. The yellow curve is a smoothed depiction using 5-yr moving average to capture the variations in the data. The $95 \%$ confidence interval envelope is shown by cyan color (annual values exceed those limits). 

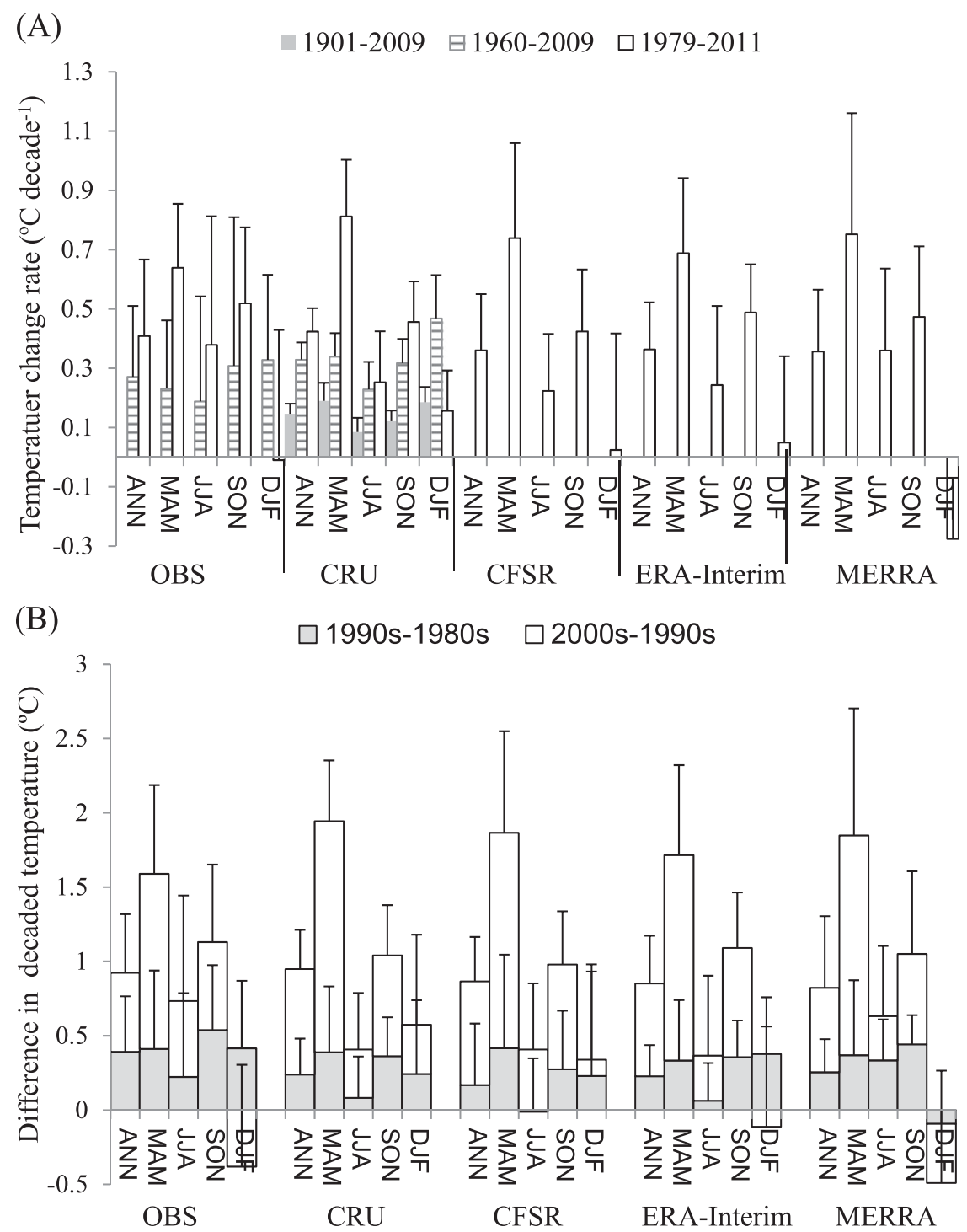

FIG. 4. Annual and seasonal changes in near-surface air temperature (a) for 1979-2011,19602009, and 1901-2009, calculated using linear fitting and (b) from 1980 to 2011 as revealed by decadal differences [i.e., (1990s - 1980s) vs (2000s -1990s); Eq. (1)]. Note that the two periods, 1990s - 1980s and 2000s - 1990s, are stacked in (b). Error bars show 1 standard error in both (a) and (b).

probably anticipated. Moreover, the decadal temperature difference for seasonal and annual mean surface temperatures between the 2000s + and 1990s is $35 \%-$ $200 \%$ higher than the difference between the 1990 s and 1980 s, indicating the warming continuing into the twenty-first century (Fig. 4b). The M-K tests indicate that an overwhelming temperature increase took place in the late 1990s and early 2000s, a result again suggesting strong warming near the turn of this century (Fig. 5a).

Figure 4a also shows that the changes in seasonal temperatures are similar among the results from the
OBS, the CRU, and the three reanalysis datasets. Warming is most prominent in the spring, at rates ranging $0.64^{\circ}-0.81^{\circ} \mathrm{C}$ decade $^{-1}$ from $1979-2011$ among the datasets. Figure $4 \mathrm{~b}$ further shows that the difference of temperatures between the 2000s + and the 1990s [Eq. (1) ] accounts for $75 \%-83 \%$ of the spring warming in the last three decades, a result again indicating strong warming near the turn of this century. Except for winter, the other seasons also show significant warming from 1979 to 2011 (also see Fig. 2). Results from analysis of the OBS and MERRA data show that $3 \%-4 \%$ of the study region has experienced decrease in winter temperatures 
(A)

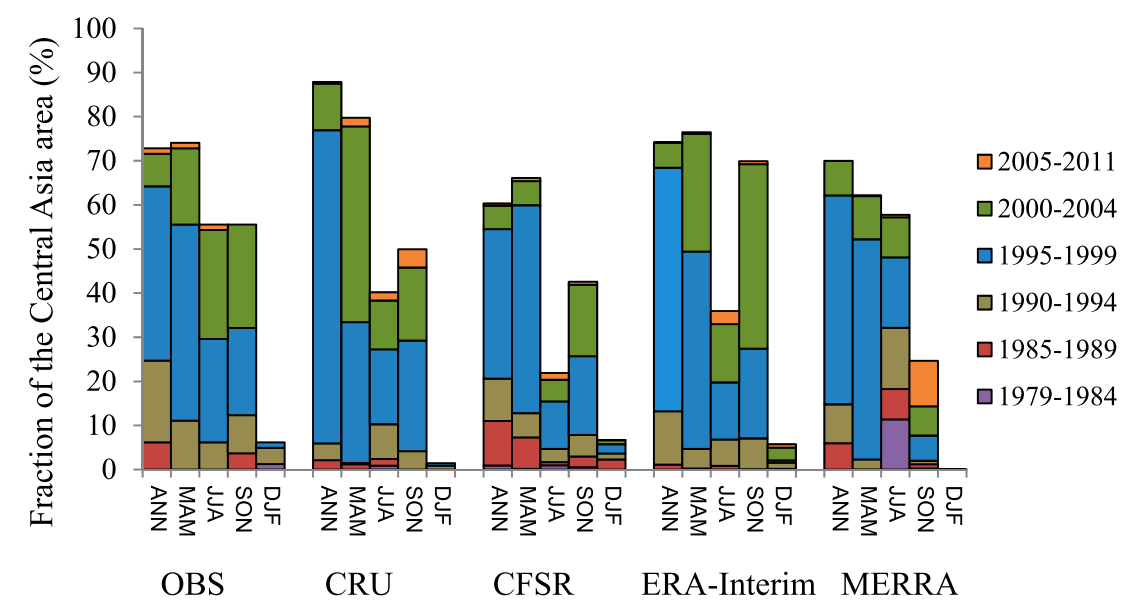

(B)

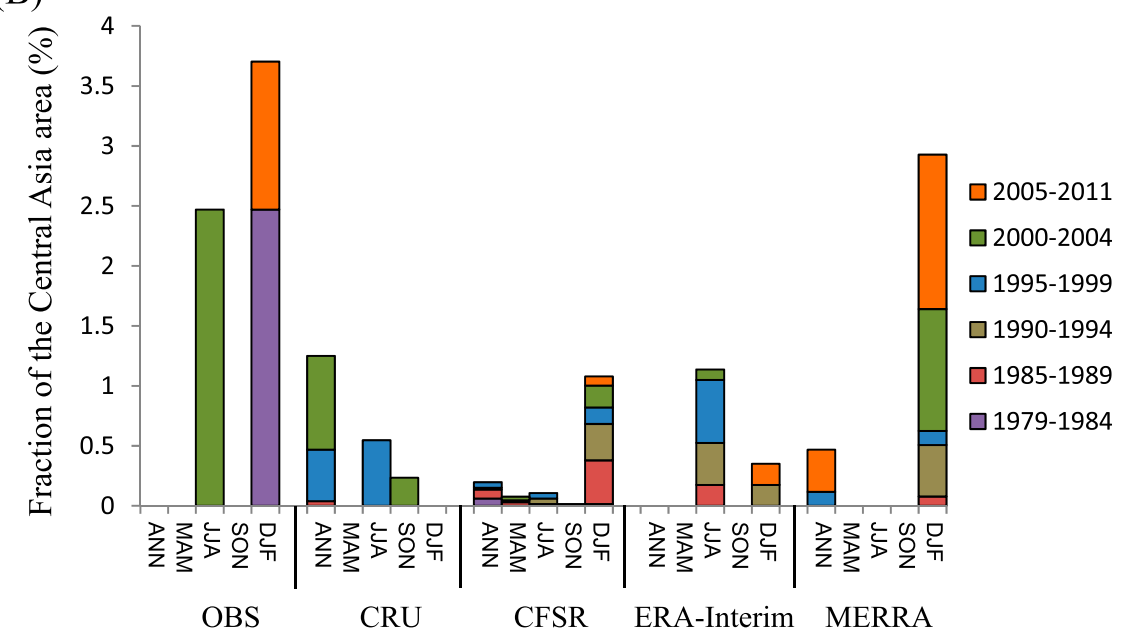

FIG. 5. Turning point (in a span of $5 \mathrm{yr}$ ) in temperature trend from 1979 to 2011 : (a) temperature increase and (b) temperature decrease.

during the last three decades. A linear fitting result of the MERRA data (Fig. 4a) suggests a cooling rate of $0.27^{\circ} \mathrm{C}_{\text {decade }}{ }^{-1}$ in mean winter temperature from 1979 to 2011. Results from decadal difference analyses [Eq. (1)] of the OBS, ERA-Interim, and MERRA show that the average winter temperature of the 2000-11 is about $0.11^{\circ}-0.39^{\circ} \mathrm{C}$ lower than that of the 1990 s in central Asia, indicating mild winter cooling near the turn of the century (Fig. 4b). The other two datasets, CFSR and CRU, show a slight increase in winter temperatures (magnitude smaller than one standard error).

\section{c. Spatial variation in temperature changes}

Although the analysis of average temperatures in the study region shows similar variations between the OBS and the CRU and the three reanalysis datasets, there are dissimilarities in their spatial patterns. Figures $6 b$ and $6 c$ show that the CFSR and ERA-Interim have similar spatial pattern of temperature change with relatively strong increase in the northern and southwestern Turanian plain and in eastern Xinjiang. This pattern is largely similar to that shown in Fig. 1b from the OBS and Fig. 6a from the CRU data, but different from the result derived from the MERRA dataset (Fig. 6d). The major differences are in Xinjiang, where the MERRA result shows little change in temperature, and in northern and eastern Kazakhstan where there is widespread increase in temperature in the MERRA result.

We further examined and compared the evolution of the decadal temperature change pattern from the 1980s to 2000 s + derived from all the datasets. The differences of the decadal averaged near-surface air temperatures in 

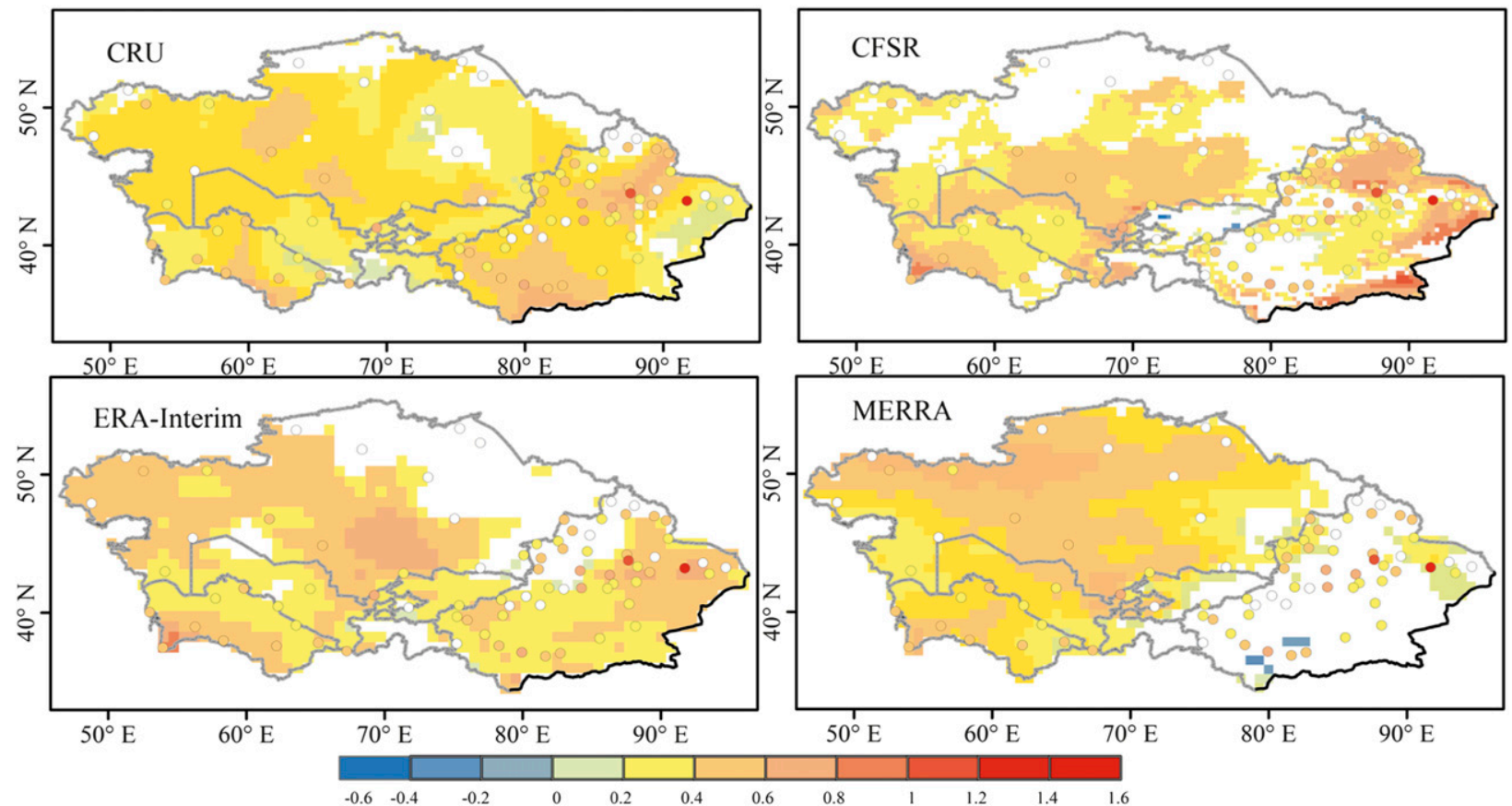

FIG. 6. Spatial pattern of annual temperature change rates $\left({ }^{\circ} \mathrm{C} \mathrm{decade}{ }^{-1}\right)$ in central Asia from 1979 to 2011 based on linear trend fitting. Circles show the locations of the meteorological stations and the filling color indicates the rate of change from available observational data. Note that the white areas and circles indicate temperature changes that are insignificant at the $95 \%$ level.

the study region provide additional temporal details for the 33-yr (1979-2011) temperature trends shown in Fig. 6. The changes in surface temperature from the 1980s to the 1990s for the datasets are shown in Fig. 7. They show that 1) different datasets have yielded similar results in temperature change in those two decades although the MERRA data have some excessive warming in the northern tier of Kazakhstan, and 2) there was cooling from the 1980s to the 1990s in south-central and central CAS region with varying but small magnitudes. The cooling trend reversed in 2000-11 as shown in Figs. $7 \mathrm{~b}, \mathrm{~d}$,f,h when the five central Asian states showed warming at large magnitudes.

Figure 7 also shows big differences in temperature variation in eastern central Asia (Xinjiang, China). The area shows noticeable warming from the 1980s to the 1990s while part of the CAS was experiencing weak cooling in the same period. From the 1990s to the 2000s + Xinjiang had weaker warming with some locations showing cooling while nearly the entire CAS had substantial warming. Results from the M-K tests suggest that temperature warming in many areas in Xinjiang became noticeable in the 1980s, consistent with and supporting the results in Fig. 7.

The EOF analysis helps encapsulate the information about the spatiotemporal variations in the near-surface air temperature in central Asia previously described.
Results of the EOF analysis are summarized in Table 3. Since the first EOF mode (EOF-1) contributes 63\%$73 \%$ of the spatial variability in the annual temperature variation during 1979-2011, only EOF-1 and its coefficient (PC-1) are shown in Fig. 8. Significant at the $95 \%$ confidence level, EOF-1 reaffirms that the temperature changes in CAS and eastern central Asia (i.e., Xinjiang) are different as suggested in Figs. 7 and 8. These results suggest the importance of regional processes in local climate across the arid and semiarid central Asia. The EOF-1 in Figs. 9a,c,g,e further shows that the variability of the surface temperatures in central Asia decreases from the northwest to the southeast. Along this gradient, northern Kazakhstan has large variability in surface temperature whereas southwestern Xinjiang has small variability.

We further extended the analysis of near-surface air temperature change in central Asia to changes in the temperature for the vegetated (VG), nonvegetated (NV), and glacier-covered (GC) areas in the region. The results are summarized in Table 4. Again, the three reanalysis datasets show significant warming in nearsurface temperatures for all land cover types. While differences exist among rates of temperature changes for $\mathrm{VG}, \mathrm{NV}$, and $\mathrm{GC}$ areas, the rates are similar for the CFSR and ERA-Interim datasets. The results from MERRA suggest a higher warming rate in VG areas 

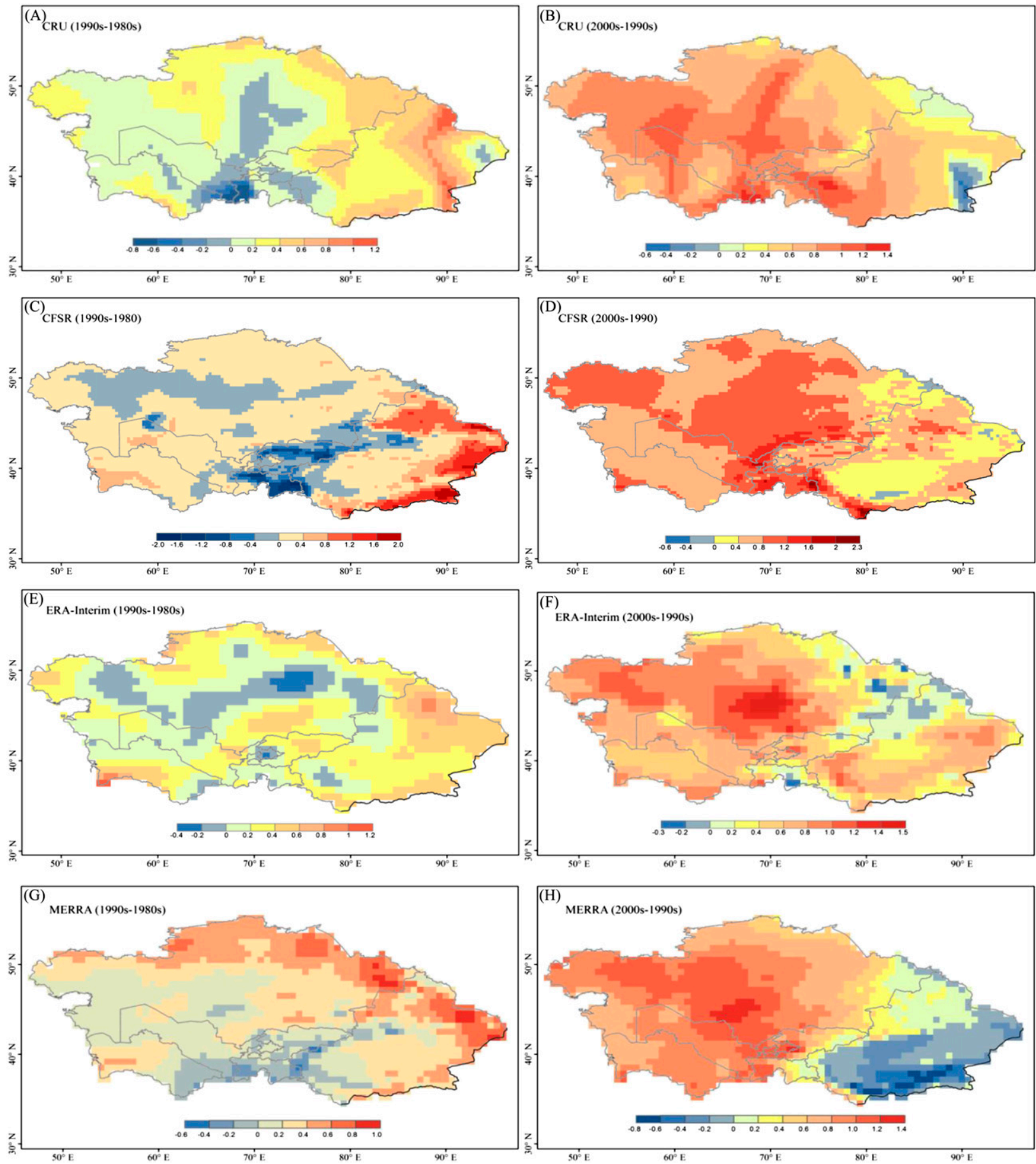

FIG. 7. Spatial pattern of differences in decadal mean temperature $\left({ }^{\circ} \mathrm{C}\right)$ for different datasets: (left) the difference between the 1990 s and 1980 s and (right) the difference between the 2000s + (2000-11) and 1990s: datasets (top)-(bottom) CRU, CFSR, ERA-Interim, and MERRA.

than the other two datasets. Additionally, results from MERRA show that the warming rate of $0.41^{\circ} \mathrm{C}$ decade $^{-1}$ in the VG area is (statistically) significantly higher than the warming rate of $0.24^{\circ} \mathrm{C} \mathrm{decade}^{-1}$ in the glacier-covered areas.
The change in the temperature trend as function of elevation is also examined using the datasets. Figure 9 shows such elevation dependence of the annual and seasonal near-surface air temperature in the Tian Shan mountainous area. In general, the effect of elevation 
TABLE 3. The eigenvalues $\lambda$ and variance contributions $R(\%)$ of the EOF analyses. The numeric subscripts indicate the EOF modes $1-4$.

\begin{tabular}{lccrrrrr}
\hline \multicolumn{1}{c}{ Datasets } & \multicolumn{1}{c}{$\lambda_{1}$} & $R_{1}$ & \multicolumn{1}{c}{$\lambda_{2}$} & \multicolumn{1}{c}{$R_{2}$} & \multicolumn{1}{c}{$\lambda_{3}$} & $R_{3}$ & $\lambda_{4}$ \\
\hline CRU & 1186.55 & 72.50 & 145.25 & 8.88 & 132.28 & 8.08 & 39.34 \\
CFSR & 3490.33 & 62.99 & 577.43 & 10.42 & 355.58 & 6.06 & 280.59 \\
ERA-Interim & 521.21 & 69.05 & 77.59 & 10.28 & 64.68 & 8.57 & 17.82 \\
MERRA & 917.21 & 70.43 & 132.36 & 10.16 & 82.68 & 6.35 & 37.32 \\
\hline
\end{tabular}

damps the warming in the surface temperature. The results from the CFSR dataset show stronger altitude effects (with correlation coefficients as high as 0.41) than the results from MERRA and ERA-Interim. Our further analysis shows that this difference is not due to the high resolution of CFSR, because even when the CFSR and MERRA were rescaled to match the coarse resolution of ERA-Interim $\left(0.75^{\circ} \times 0.75^{\circ}\right)$ the general pattern is unchanged (see Table S3 in the supplementary material). CFSR always has stronger altitude effects than the other two reanalysis datasets. Also shown in the results of the CFSR data is that the effect of elevation is most prominent in spring, when the decadal mean warming rate is damped by $0.22^{\circ} \mathrm{C}$ with every $1-\mathrm{km}$ increase in elevation.

\section{Discussion}

\section{a. Comparison of this study with prior studies}

Our results show a strong increase in the near-surface air temperature at $0.39^{\circ} \mathrm{C} \mathrm{decade}^{-1}$ averaged in central Asia during the period from 1979 to 2011. This rate of change is larger than the rate averaged for global land areas (i.e., $0.27^{\circ}-0.31^{\circ} \mathrm{Cdecade}^{-1}$ from 1979 to 2005 ) (Table 5; Brohan et al. 2006; Smith and Reynolds 2005) and is about twice as large as the warming rate in Europe (Simmons et al. 2004). This rate is comparable to the observed warming trend in China $\left[0.25^{\circ}-0.34^{\circ} \mathrm{C} \mathrm{decade}^{-1}\right.$ according to Ren et al. (2005) and Li et al. (2011, 2012)] and also is in line with the central Asian averaged warming rate in the 50 years from 1960 to $2009,0.30^{\circ} \mathrm{Cdecade}^{-1}$. It is worth of noting that this rate is much smaller than the rate averaged over China, $0.52^{\circ} \mathrm{Cdecade}^{-1}$, reported in Wang and Gong (2000). This difference results from different years used in these two studies. Wang and Gong (2000) used data from 1979 to 1998. Because 1998 was an extraordinarily warm year in China, ending the analysis period in that year could have yielded a larger rate of temperature change.

Our extension of the analysis indicates that central Asian temperature has increased at a rate of $0.15^{\circ} \mathrm{Cdecade}^{-1}$ from 1901 to 2011, which is comparable to the $0.17^{\circ} \mathrm{C} \mathrm{decade}^{-1}$ temperature increase in Russia (Kattsov et al. 2008) but twice as large as the global mean rate of $0.07^{\circ}-0.08^{\circ} \mathrm{Cdecade}^{-1}$ over the same period (Brohan et al. 2006; Smith and Reynolds 2005). Additional comparisons of the results from our study to some relevant previous studies are summarized in Table 5 .

A breakdown of the decadal temperature change in the recent 30 years further suggests an accelerated warming in the past three decades (Table 4; Figs. 3b,c and 7). This strong warming trend agrees with the predictions from global climate model (GCM) simulations, which suggested that central Asia will have a warming rate well above the global mean in the twenty-first century (Trenberth et al. 2007). For example, model simulations with eight GCMs (Pollner et al. 2008) and four coupled atmosphere-ocean GCMs (AOGCMs; Lioubimtseva and Henebry 2009) projected the temperature in central Asia to increase with a rate of $0.29^{\circ}-$ $0.48^{\circ} \mathrm{C}$ decade $^{-1}$ in the twenty-first century, comparable to the recent warming rate $\left(0.39^{\circ} \mathrm{Cdecade}^{-1}\right)$ found in this study (Table 5).

\section{b. A shift in seasonal temperature change pattern in recent decades and its impacts}

It has been reported that temperature increase in many regions around the world and in central Asian countries has occurred most prominently in the winter months. Winter warming contributed strongly to the annual temperature increase (Zoi Environment Network 2009; Huang et al. 2005; Li et al. 2011; Ren et al. 2005; Trenberth et al. 2007). Climate model projected temperature change in the twenty-first century also suggested that the largest temperature increase would occur in winter in the central Asian states (e.g., Kattsov et al. 2008; Lioubimtseva and Henebry 2009). Our study, however, has revealed a dramatic shift of the largest temperature increase in central Asia from its winter to spring season. During most of the twentieth century, surface air temperature on average has been increasing at larger rate in winter than in other seasons. This situation has changed in the recent 33 years. From 1990s to 2000 s + the largest increase in seasonal temperatures has been found in spring months (Fig. 4b) whereas the winter temperature increase has been leveling off.

Our results further show that large rate of spring temperature increase up to $1.2^{\circ}-2.2^{\circ} \mathrm{Cdecade}^{-1}$ has 

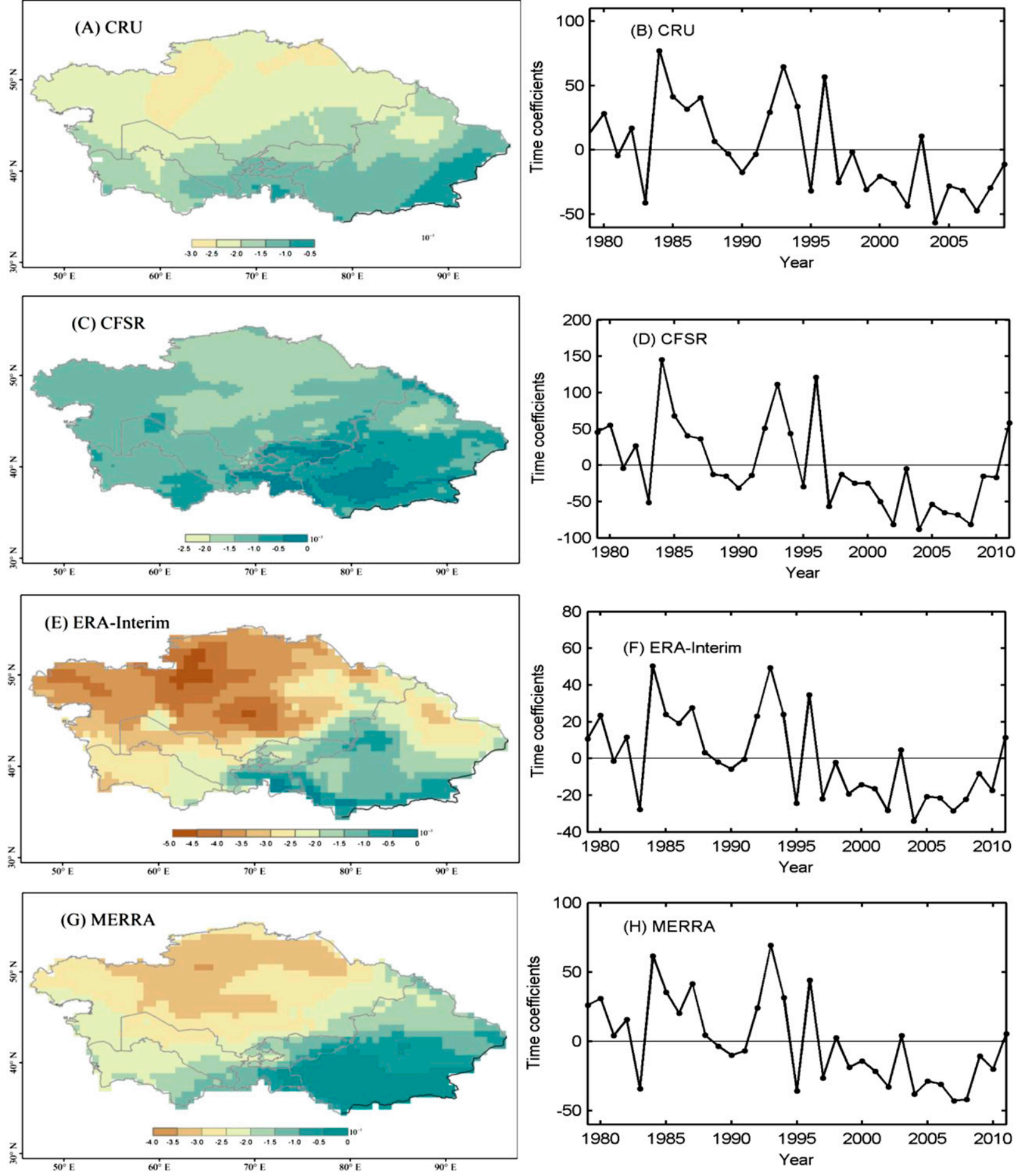

FIG. 8. (left) EOF-1 of the annual temperature anomalies $\left({ }^{\circ} \mathrm{C}\right)$ and (right) the corresponding time series from the four datasets: (a),(b) CRU, (c),(d) CFSR, (e),(f) ERA-Interim, and (g),(h) MERRA.

concentrated in the central part of the central Asian states (Fig. 10). This shift of the largest warming rate of the seasonal temperature from winter to spring may have started affecting the ecosystems in central Asia.
Strong spring warming could stimulate early leaf onset, as observed in Europe during the last three decades (Menzel and Fabian 1999; Menzel 2000; Menzel et al. 2006). Propastin et al. (2008) have detected a significant 

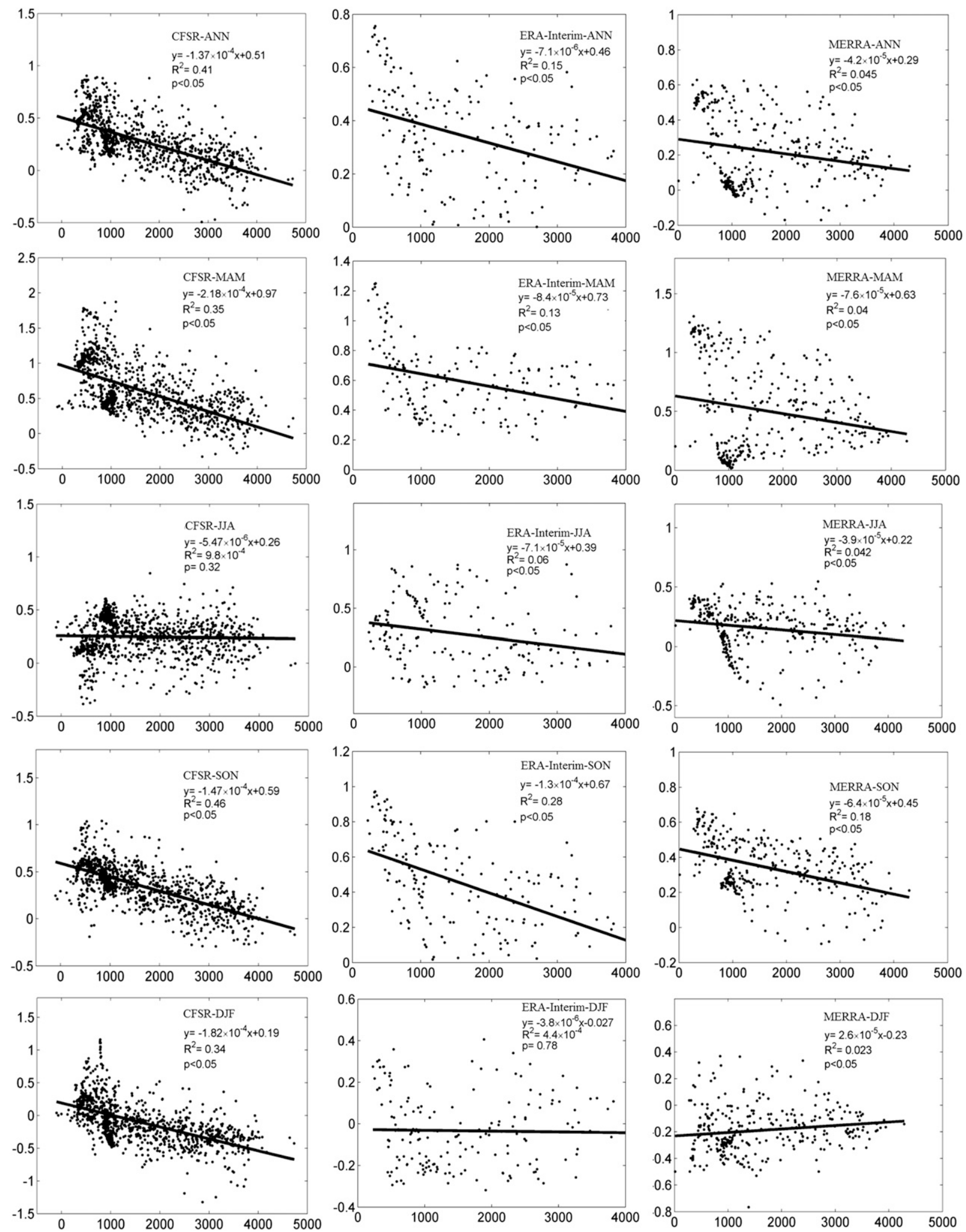

FIG. 9. (top)-(bottom) Annual and seasonal temperature trends from 1979 to 2011 (ordinate, ${ }^{\circ} \mathrm{C}$ decade ${ }^{-1}$ ) as function of elevation (abscissa, m MSL) in the Tian Shan mountainous area (see Fig. 1a for the geographical location of this area) based on (left)-(right) CFSR, ERA-Interim, and MERRA datasets. ANN indicates annual, MAM spring, JJA summer, SON fall, and DJF winter. 
TABLE 4. Rates of temperature change $\left({ }^{\circ} \mathrm{Cdecade}^{-1}\right)$ from 1979 to 2011 in central Asia (CA), and in vegetated (VG), nonvegetated $(\mathrm{NV})$, and glacier-covered (GC) areas in central Asia.

\begin{tabular}{lcccc}
\hline \hline \multicolumn{1}{c}{ Dataset } & CA & VG & NV & GC \\
\hline CRU & 0.42 & 0.42 & 0.42 & 0.42 \\
CFSR & 0.36 & 0.37 & 0.34 & 0.33 \\
ERA-Interim & 0.36 & 0.36 & 0.37 & 0.33 \\
MERRA & 0.36 & 0.41 & 0.29 & 0.24 \\
\hline
\end{tabular}

increase $(13.58 \%)$ in vegetation growth in terms of the normalized difference vegetation index (NDVI) in central Asian states from 1982 to 2003, which they attributed largely to the increase in spring temperatures. Furthermore, the strong spring warming in the central Asian states was reported to have increased risks of natural hazards such as flooding and formation and outburst of ice dams in major rivers (Michael 2011; Siegfried et al. 2012).

\section{c. Elevation dependence of the near-surface air temperature change in central Asia}

A recent review by Rangwala and Miller (2012) suggests that elevation dependence in temperature change varies under spatial and temporal conditions. Some prior studies using observational data have shown positive correlations of the elevation with the warming rate in the European Alps (Beniston and Rebetez 1996), Nepal Himalayas (Shrestha et al. 1999), Yunnan Plateau in China (Fan et al. 2011), and the Tibet Plateau (Liu and Chen 2000). The warming is more pronounced at higher elevations in those areas. This positive correlation of the warming rate and elevation is also found in most model simulation results (Giorgi et al. 1997; Chen et al. 2003). However, our analysis shows significant negative correlations (up to $R^{2}=0.41$ ) between elevation and the warming rate in the Tian Shan mountainous area of central Asia during 1979-2011 (Fig. 9). A similar negative correlation also was found in the tropical Andes in Vuille and Bradley (2000) and Vuille et al. (2003).

According to Liu and Chen (2000), a decrease in spring snow cover at higher elevations could lower the surface albedo and initiate a positive feedback on the surface and near-surface air temperatures, leading to more pronounced warming at high altitudes. This mechanism has been confirmed by model simulations (Chen et al. 2003) and was used to explain the observed positive correlation between the warming rate and elevation in the Tibetan Plateau (Liu and Chen 2000). However, it is difficult to explain why in Tian Shan, a region not far from the Tibetan Plateau, we found a completely opposite pattern with warming rate decreasing with elevation. Some possible factors attributing to these differences could include the effectiveness of the feedback as the elevation increase (into the permafrost elevation or higher) and regional atmospheric circulation. A conclusive understanding of this relationship will require a more comprehensive network of climate monitoring in mountainous regions and detailed modeling (Rangwala and Miller 2012).

\section{d. Effects of land-use changes}

Although the temperature change in central Asia well matched the recent warming in the North Hemisphere, it could also be influenced by land-use changes such as irrigation and urbanization at local scales (Lioubimtseva et al. 2005). It has been widely observed that the oases in our study region have lowered temperature comparing to the surrounding desert (i.e., oasis cooling effect), mainly due to the evaporative cooling caused by plant transpiration and irrigation (Kai et al. 1997; Han 1999). According to the statistics in Dukhovny et al. (2009), both the intensity and total water of irrigation in the five central Asian states decreased from 1994 to 2008 (Fig. 11a), possibly due to deintensification of agriculture following the collapse of the former Soviet Union (Lioubimtseva and Henebry 2009). Therefore, the observed temperature rise could be partially caused by local climate effect from declining irrigation intensity in the CAS. To investigate this possibility, we first identified all the meteorological stations located in or within $5 \mathrm{~km}$ of the irrigated land in CAS based on the United Nations Food and Agriculture Organization (FAO) global map of irrigated land (Siebert et al. 2007). We then paired them to the closest stations in nonirrigated land (Fig. 11b). Although the advective effect of oases on local climate fades rapidly with distance (Taha et al. 1991), there has been evidence that the effects could still be considerable within $1-10 \mathrm{~km}$ from the vegetated areas (DeVries 1959; Zhang and Zhao 1999), and the typical width of the oasis-desert ecotone in the temperate desert of central Asia is about $4 \mathrm{~km}$ (Han 1999). Therefore, we used a $5-\mathrm{km}$ buffer around the irrigated land to identify the meteorological stations where local conditions or observations may have been influenced by changes in irrigation intensity since the early 1990s. Comparisons between the temperature change rates of those "oasis stations" and the control sites (i.e., the selected stations outside the irrigated land) are shown in Table 6. Although the mean warming rate of the oasis stations was slightly higher than the mean rate of the control sites $\left(0.38^{\circ}\right.$ versus $\left.0.34^{\circ} \mathrm{Cdecade}^{-1}\right)$, the difference was not significant ( $p$ value $>0.05 ; N=14$ ) according to a paired $t$ test. There was also no significant difference between the mean warming rates of the oasis stations and all other stations in central Asia according 


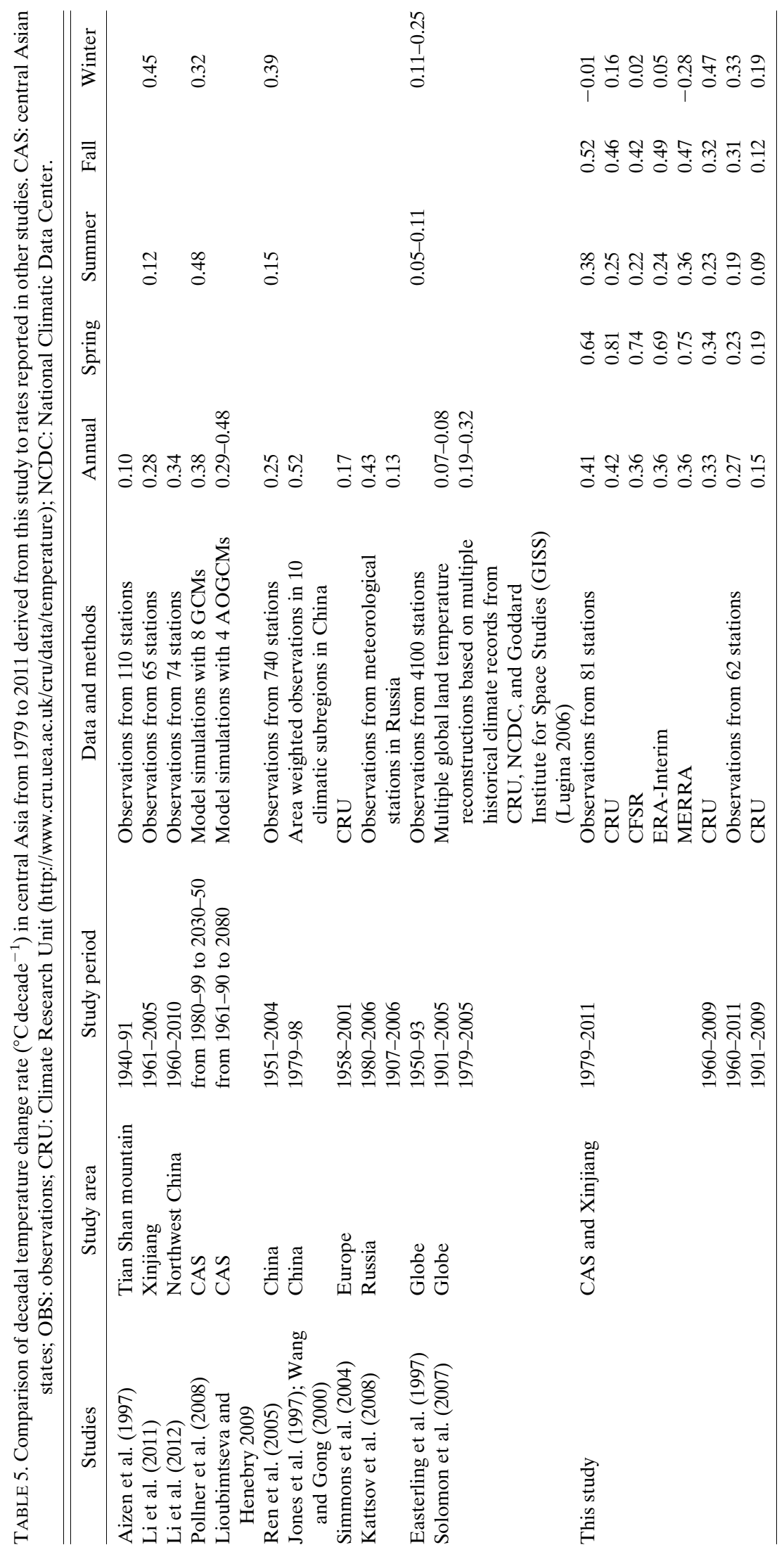



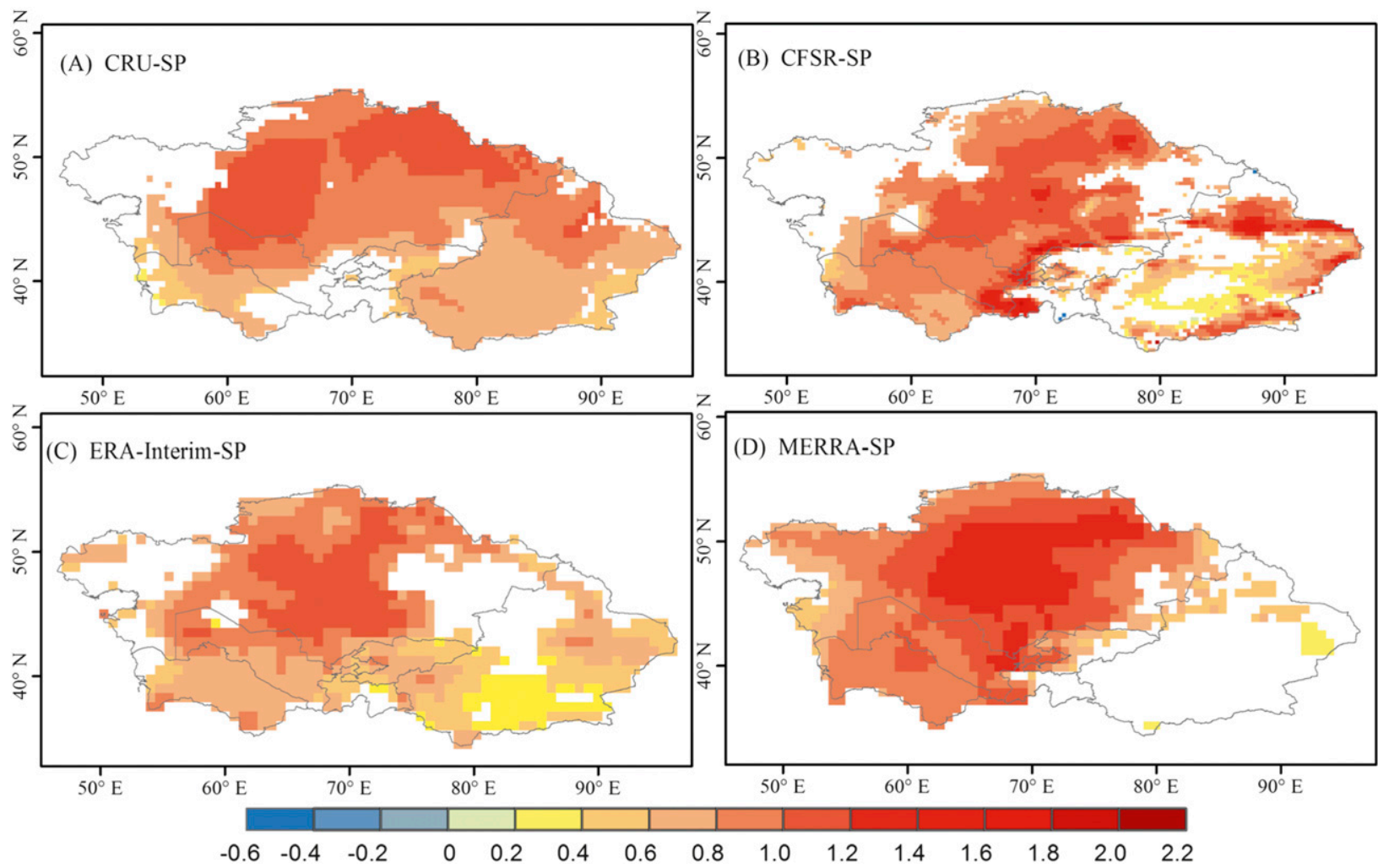

FIG. 10. Spatial pattern of spring warming rate $\left({ }^{\circ} \mathrm{C} \mathrm{decade}^{-1}\right)$ from 1979 to 2011 in central Asia according to the four reanalysis datasets: (a) CRU, (b) CFSR, (c) ERA-Interim, and (d) MERRA.

to unpaired $t$ tests. Finally, when comparing the mean temperatures between the early 1990s (1990-95) and late 1990s (1995-2000), we found that the warming in the oasis stations was actually smaller than that in the other stations $\left(0.66^{\circ}\right.$ versus $\left.0.84^{\circ} \mathrm{C}\right)$. Our analysis, therefore, detected no significant positive effect from de-intensification of agriculture following the collapse of the former Soviet Union in the early 1990s on the observed temperature increase in central Asia.

We used a similar approach to investigate whether urbanization in the study region may have affected the observed temperature change. First, all urban stations in central Asia were identified with the 500-m-resolution global urban land map developed by Schneider et al. (2009). Then, these urban stations were paired to the closest rural stations in central Asia (Fig. 12a; Table 7). In Fig. 12, the crosses mark the 22 meteorological stations located in urban areas. Although the population increased by about $45.7 \%$ in those cities in 1980-2000 (Fig. 12b), paired $t$ test showed no significant differences in temperature change rates between the urban and rural stations ( $p$ value $>0.05 ; N=22$ ). Unpaired $t$ test values also indicated no significant difference in temperature change rates between the urban stations and all the other stations in the study region. These test results thus suggest no significant effect from urbanization on the observed temperature change in central Asia.

\section{Conclusions}

Temperature observations at meteorological stations, the CRU dataset, and three recently developed highresolution reanalysis datasets, CSRF, MERRA, and ERA-Interim, were used in this study to evaluate the near-surface air temperature change in central Asia from 1979 to 2011. The reanalysis datasets of CSRF, MERRA, and ERA-Interim were first examined for their accuracy in describing the temperature variations in the study region. Comparisons of these datasets with qualitycontrolled in situ observations showed that the datasets are fairly accurate by several statistical measures, although minor differences exist among these datasets and the observations. While these test results are important for validation of the datasets they justify the use of these datasets in our analysis of the temperature variation in central Asia. Their high-resolution spatial coverage overcomes the difficulty of the ground observations from sparse stations in the region and allows us to examine and understand central Asian temperature variations (Lioubimtseva et al. 2005; Lioubimtseva and Cole 2006). 
(A)

$\square$ Total water (G Ton) $\quad$ Intensity $\left(\mathrm{Ton} / \mathrm{km}^{2}\right)$

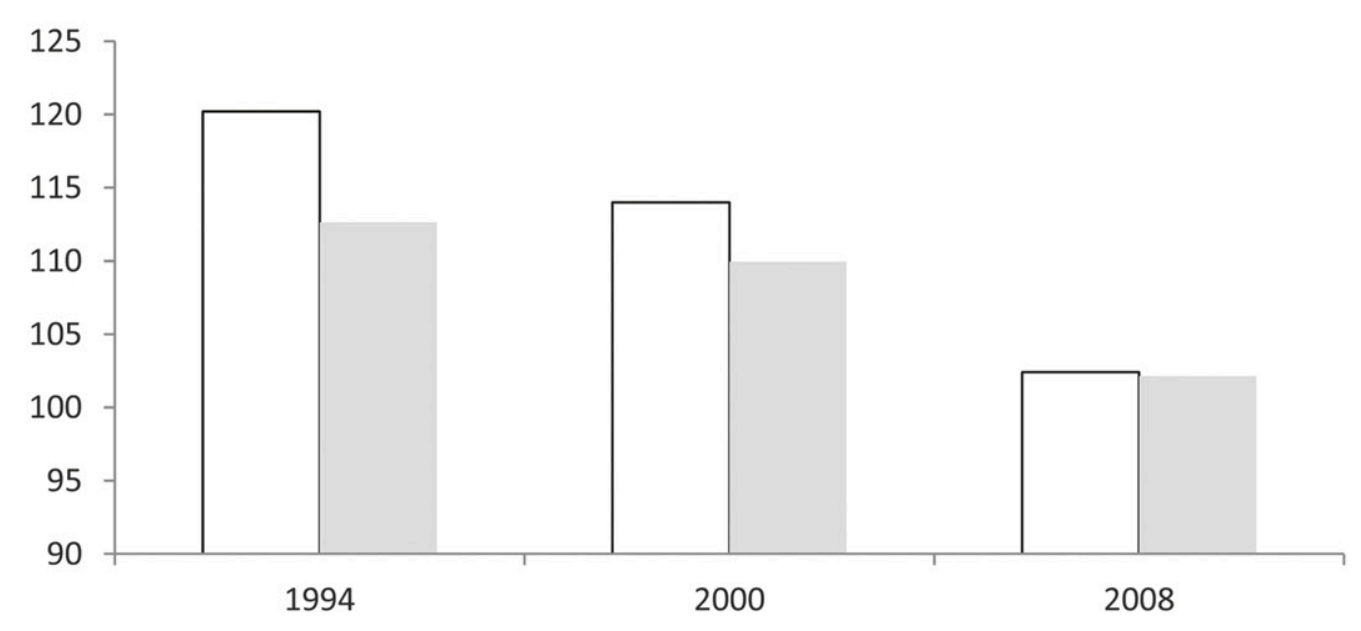

(B)

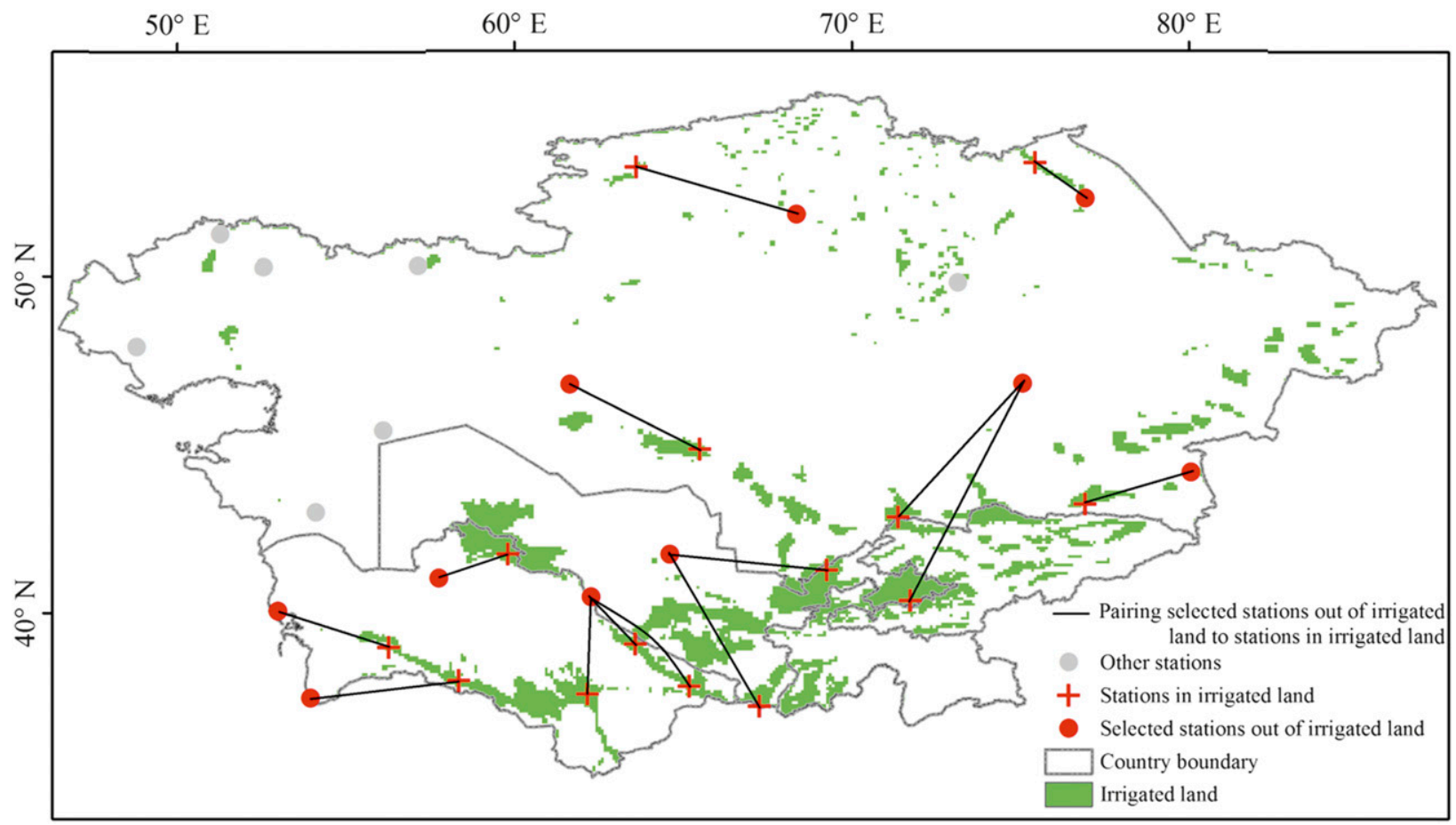

FIG. 11. (a) Changes in total water for irrigation and irrigation intensity in the five central Asian states from 1994 to 2008 (Dukhovny et al. 2009) indicating a declining irrigation in the region. (b) Pairing of meteorological stations located in the irrigated land with the closest stations outside the irrigated land. 
TABLE 6. Comparison of the observed temperature change rates from 1979 to 2011 between stations in irrigated land and the selected stations out of irrigated land in the five central Asian states.

\begin{tabular}{|c|c|c|c|}
\hline \multicolumn{2}{|c|}{$\begin{array}{c}\text { Stations in irrigated } \\
\text { land }\end{array}$} & \multicolumn{2}{|c|}{$\begin{array}{l}\text { Selected stations outside of irrigated } \\
\text { land }\end{array}$} \\
\hline ID & $\begin{array}{l}\text { Warming rate } \\
\left({ }^{\circ} \mathrm{C} \text { decade }{ }^{-1}\right)\end{array}$ & ID & $\begin{array}{l}\text { Warming rate } \\
\left({ }^{\circ} \mathrm{C} \text { decade }{ }^{-1}\right)\end{array}$ \\
\hline 12 & 0.33 & 23 & 0.31 \\
\hline 7 & 0.24 & 19 & 0.10 \\
\hline 176 & 0.11 & 151 & 0.28 \\
\hline 261 & 0.16 & 106 & 0.20 \\
\hline 138 & 0.50 & 109 & 0.41 \\
\hline 193 & 0.30 & 106 & 0.20 \\
\hline 223 & 0.52 & 241 & 0.37 \\
\hline 236 & 0.68 & 224 & 0.34 \\
\hline 299 & 0.27 & 260 & 0.39 \\
\hline 305 & 0.46 & 273 & 0.42 \\
\hline 334 & 0.52 & 350 & 0.57 \\
\hline 346 & 0.41 & 260 & 0.39 \\
\hline 338 & 0.44 & 260 & 0.39 \\
\hline 356 & 0.41 & 224 & 0.34 \\
\hline
\end{tabular}

The consensus of these datasets and available in situ observations indicates accelerated warming at the average rate of $0.39^{\circ} \mathrm{Cdecade}^{-1}$ in central Asia from 1979 to 2011, which is stronger than the mean rate of temperature change for global land areas (e.g., Brohan et al. 2006; Smith and Reynolds 2005) and other regions (Simmons et al. 2004; Ren et al. 2005; Li et al. 2011, 2012). Moreover, the warming rate in central Asia in the first 12 years of the twenty-first century is larger than that of the previous decades. This increase rate in central
Asia in the early twenty-first century is comparable to that averaged for Russia and for China (Brohan et al. 2006; Smith and Reynolds 2005) and is larger than that averaged for Europe (Simmons et al. 2004). In addition to showing the spatial pattern of the temperature change we further identified that the maximum rate of temperature increase in central Asia occurred in the central areas of the central Asian states.

We also found that the seasonal pattern of the rise in near-surface air temperature has changed in central Asia in the recent decades. While winter warming was most prominent among all the seasons during the most part of the twentieth century (Zoi Environment Network 2009; Huang et al. 2005; Li et al. 2011; Ren et al. 2005; Trenberth et al. 2007), the winter warming has weakened and even reversed in some areas over time. Mean winter temperature in the early twenty-first century is cooler than in the 1990s. Meanwhile, the spring temperature has been steadily increasing from 1979 to 2011, with a larger increase rate in the early twenty-first century. The spring warming has replaced the winter warming as the major contributor to the annual temperature rise. This shift of the strong warming from the dormant winter season to the germination spring season could result in changes in phenology of plants in the region and also raise the risk of spring flooding (Michael 2011; Siegfried et al. 2012).

The magnitude of temperature increase is found shrinking significantly with elevation, a result different from the results of some previous studies in regions surrounding central Asia (Beniston and Rebetez 1996;

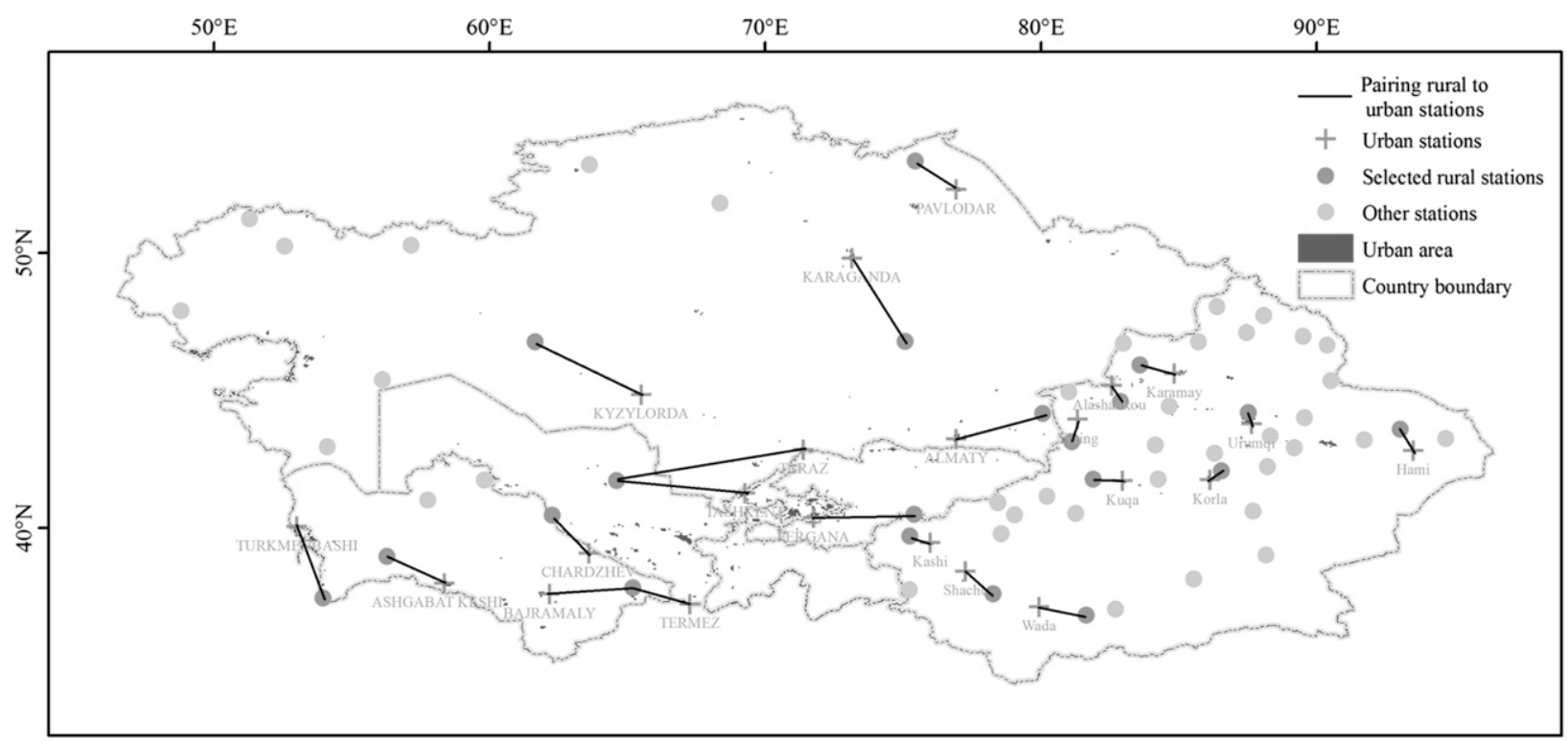

FIG. 12. Pairs of meteorological stations located in the urban areas and the closest rural stations. 
TABLE 7. Comparison of the observed temperature change rates from 1979 to 2011 between urban station and the closest rural station in central Asia.

\begin{tabular}{|c|c|c|c|}
\hline \multicolumn{2}{|c|}{ Urban station } & \multicolumn{2}{|c|}{ Rural station } \\
\hline ID & $\begin{array}{l}\text { Warming rate } \\
\left({ }^{\circ} \mathrm{C} \text { decade }^{-1}\right)\end{array}$ & ID & $\begin{array}{l}\text { Warming rate } \\
\left({ }^{\circ} \mathrm{Cdecade}^{-1}\right)\end{array}$ \\
\hline 273 & 0.42 & 350 & 0.57 \\
\hline 334 & 0.52 & 305 & 0.46 \\
\hline 346 & 0.41 & 338 & 0.44 \\
\hline 299 & 0.27 & 260 & 0.39 \\
\hline 138 & 0.50 & 109 & 0.41 \\
\hline 356 & 0.41 & 338 & 0.44 \\
\hline 236 & 0.68 & 224 & 0.34 \\
\hline 193 & 0.30 & 224 & 0.34 \\
\hline 261 & 0.16 & 258 & 0.27 \\
\hline 54 & 0.03 & 106 & 0.20 \\
\hline 287 & 0.55 & 279 & 0.36 \\
\hline 19 & 0.10 & 7 & 0.24 \\
\hline 176 & 0.11 & 151 & 0.28 \\
\hline 319 & 0.32 & 345 & 0.49 \\
\hline 357 & 0.64 & 360 & 0.40 \\
\hline 159 & 0.45 & 179 & 0.41 \\
\hline 131 & 0.30 & 144 & 0.45 \\
\hline 225 & -0.11 & 219 & 0.29 \\
\hline 125 & 0.20 & 120 & 0.55 \\
\hline 220 & 0.39 & 212 & 0.37 \\
\hline 162 & 1.01 & 150 & 0.43 \\
\hline 196 & 0.21 & 167 & 0.95 \\
\hline
\end{tabular}

Shrestha et al. 1999; Fan et al. 2011; Liu and Chen 2000) and from most model simulations (Giorgi et al. 1997; Chen et al. 2003). This different result and further understanding of underlying mechanisms for the observed temperature change and its spatial heterogeneity in central Asia will continue to elude us in the absence of comprehensive networks of climate monitoring in this vast arid and semiarid region (Rangwala and Miller 2012).

It has been suggested that the de-intensification of agriculture following the collapse of the Soviet Union in early 1990s and urbanization may be influencing the observed temperature change in irrigated or urban areas (Zhou et al. 2004; Ren et al. 2008; Lioubimtseva and Henebry 2009). Our analysis, however, did not find significant contributions from urbanization or declined irrigation to temperature change in the study region. This finding assures the relevance of our results in describing the surface temperature variations in central Asia.

Acknowledgments. This study was supported by grants from Chinese National Basic Research Program (2014CB954204), and the International Science \& Technology Cooperation Program of China (2010DFA92720-10) and the National Basic Research Programs of China (2009CB825105). We thank Dr. Qingxiang Li from the
National Meteorological Information center, China Meteorological Administration, and Mr. Gang Yin and Ms. Yan Yan from the Xinjiang Institute of Ecology and Geography, Chinese Academy of Sciences for their assistance during this study. We also thank the editor and reviewers for their valuable comments on this manuscript. The authors are grateful to Earth System Science Data Sharing Platform, Xinjiang and Central Asian scientific data sharing platform. Q. Hu was supported by USDA Research Project NEB-38-088.

\section{REFERENCES}

Aguilar, E., I. Auer, M. Brunet, T. C. Peterson, and J. Wieringa, 2003: Guidance on metadata and homogenization. WMO Tech. Doc. TD 1186 (WCDMP 53), 51 pp. [Available online at http://www. wmo.int/pages/prog/wcp/wcdmp/wcdmp_series/.]

Aizen, V. B, and Coauthors, 1997: Climatic and hydrologic changes in the Tien Shan, central Asia. J. Climate, 10, 13931404.

Alexandersson, H. A., 1986: Homogeneity test applied to precipitation data. J. Climatol., 6, 661-675.

Arino, O., J. Ramos, V. Kalogirou, P. Defourny, and F. Achard, 2010: GlobCover 2009. Proc. ESA Living Planet Symp., Bergen, Norway, ESA, SP-686.

Bao, X., and F. Zhang, 2012: Evaluation of NCEP-CFSR, NCEPNCAR, ERA-Interim, and ERA-40 reanalysis datasets against independent sounding observations over the Tibetan Plateau. J. Climate, 26, 206-214.

Beniston, M., and M. Rebetez, 1996: Regional behavior of minimum temperatures in Switzerland for the period 1979-1993. Theor. Appl. Climatol., 53, 231-243.

Blender, R., and K. Fraedrich, 2003: Long time memory in global warming simulation. Geophys. Res. Lett., 30, 1769, doi:10.1029/ 2003 GL017666.

Blyth, S., B. Groombridge, I. Lysenko, L. Miles, and A. Newton, cited 2009: Mountain watch. UNEP World Conservation Monitoring Centre, 80 pp. [Available online at http://www. unep-wcmc.org/biodiversity-series-12_113.html.]

Bordi, I., K. Fraedrich, M. Petitta, and A. Sutera, 2006: Largescale assessment of drought variability based on NCEP/ NCAR and ERA-40 Re-Analyses. Water Resour. Manage., 20, 899-915.

Brohan, P., J. J. Kennedy, I. Harris, S. F. Tett, and P. D. Jones, 2006: Uncertainty estimates in regional and global observed temperature changes: A new data set from 1850. J. Geophys. Res., 111, D12106, doi:10.1029/2005JD006548.

Bromwich, D. H., and R. L. Fogt, 2004: Strong trends in the skill of the ERA-40 and NCEP-NCAR reanalyses in the high and midlatitudes of the Southern Hemisphere, 1958-2001. J. Climate, 17, 4603-4619.

,-- K. I. Hodges, and J. E. Walsh, 2007: A tropospheric assessment of the ERA-40, NCEP, and JRA-25 global reanalyses in the polar regions. J. Geophys. Res., 122, D10111, doi:10.1029/2006JD007859.

Chen, B., W. C. Chao, and X. Liu, 2003: Enhanced climatic warming in the Tibetan Plateau due to doubling $\mathrm{CO}_{2}$ : A model study. Climate Dyn., 20, 401-413.

Chen, X., 2012: Retrieval and Analysis of Evapotranspiration in Central Areas of Asia (in Chinese). China Meteorological Press, 214 pp. 
_ J. Bai, X. Li, G. Luo, J. Li, and B. L. Li, 2013: Changes in land use/land cover and ecosystem services in Central Asia during 1990-2009. Curr. Opin. Environ. Sustainability, 5, 116-127.

Chub, V. E., 2000: Climate Change and its Impact on the Natural Resources Potential of the Republic of Uzbekistan (in Russian). Gimet, $253 \mathrm{pp}$

Dee, D. P., and Coauthors, 2011: The ERA-Interim reanalysis: Configuration and performance of the data assimilation system. Quart. J. Roy. Meteor. Soc., 137, 553-597.

DeGaetano, A. T., 2006: Attributes of several methods for detecting discontinuities in mean temperature series. J. Climate, 19, 838-853.

Dessler, A. E., and S. M. Davis, 2010: Trends in tropospheric humidity from reanalysis systems. J. Geophys. Res., 115, D19127, doi:10.1029/2010JD014192.

DeVries, D. A., 1959: The influence of irrigation on the energy balance and the climate near the ground. J. Meteor., 16, 256-270.

Dukhovny, V., V. Sokolov, and H. Manthrithilake, 2009: Integrated water resources management: Putting good theory into real practice. Central Asian Experience. SIC ICWC Rep., 384 pp. [Available online at http://www.gwp.org/Global/ GWP-CACENA_Files/en/pdf/iwrm_monograph_e.pdf.]

Easterling, D. R., and Coauthors, 1997: Maximum and minimum temperature trends for the globe. Science, 277, 364-367.

Fan, Z.-X., A. Brauning, A. Thomas, J. B. Li, and K. F. Cao, 2011: Spatial and temporal temperature trends on the Yunnan Plateau (southwest China) during 1961-2004. Int. J. Climatol., 31, 2078-2090.

Giorgi, F., J. W. Hurrell, M. R. Marinucci, and M. Beniston, 1997: Elevation dependency of the surface climate change signal: A model study. J. Climate, 10, 288-296.

Goudie, A. S., 2002: Great Warm Deserts of the World. Oxford University Press, $444 \mathrm{pp}$.

Grotjahn, R., 2008: Different data, different general circulations? A comparison of selected fields in NCEP/DOE AMIP-II and ERA-40 reanalyses. Dyn. Atmos. Oceans, 44, 108-142.

Han, D. L., 1999: The progress of research on oasis in China (in Chinese). Sci. Geogr. Sin., 19, 313-319.

Houghton, J. T., Y. Ding, D. J. Griggs, M. Noguer, P. J. van der Linden, X. Dai, K. Maskell, and C. A. Johnson, Eds., 2001: Climate Change 2001: The Scientific Basis. Cambridge University Press, $881 \mathrm{pp}$.

Huang, M., G. Peng, L. M. Leslie, X. Shao, and W. Sha, 2005: Seasonal and regional temperature changes in China over the 50 year period 1951-2000. Meteor. Atmos. Phys., 89, $105-115$.

Jones, P. D., T. J. Osborn, and K. R. Briffa, 1997: Estimating sampling errors in large-scale temperature averages. J. Climate, 10, 2548-2568.

Kai, K., M. Matsuda, and R. Sato, 1997: Oasis effect observed at the Zhangye Oasis in Hexi Corridor, China. J. Meteor. Soc. Japan, 75, 1171-1178.

Kalnay, E., and Coauthors, 1996: The NCEP/NCAR 40-Year Reanalysis Project. Bull. Amer. Meteor. Soc., 77, 437-471.

Kattsov, V., V. Govorkova, V. Meleshko, T. Pavlova, and I. Shkolnik, 2008: Climate change projections and impacts in Russian Federation and central Asia states. North Eurasia Climate Centre, Saint Petersburg, Russia. [Available online at http://neacc. meteoinfo.ru/research/20-research.]

Kendall, M. G., 1948: Rank Correlation Methods. Hafner, 160 pp.

Kharlamova, N. F., and V. S. Revyakin, 2006: Regional climate and environmental change in Central Asia. Environmental Security and Sustainable Land Use with Special Reference to
Central Asia, H. Vogtmann and N. Dobretsov, Eds., Springer, 19-26.

Le Houerou, H. N., 2005: Book review: Botanical Geography of Kazakhstan and Middle Asia (Desert Region). Arid Land Res. Manage., 19, 89-90.

Li, B., Y. Chen, and X. Shi, 2012: Why does the temperature rise faster in the arid region of northwest China? J. Geophys. Res., 117, D16115, doi:10.1029/2012JD017953.

Li, Q. H., Y. Chen, Y. Shen, X. Li, and J. Xu, 2011: Spatial and temporal trends of climate change in Xinjiang, China. J. Geogr. Sci., 21, 1007-1018.

Li, Q. X., X. Liu, H. Zhang, C. Thomas, and R. David, 2004: Detecting and adjusting temporal inhomogeneity in Chinese mean surface air temperature data. Adv. Atmos. Sci., 21, 260-268.

Lioubimtseva, E., and R. Cole, 2006: Uncertainties of climate change in arid environments of central Asia. Rev. Fish. Sci., 14, $29-49$.

_ , and G. M. Henebry, 2009: Climate and environmental change in arid central Asia: Impacts, vulnerability, and adaptations. J. Arid Environ., 73, 963-977.

— , R. Cole, J. M. Adams, and G. Kapustin, 2005: Impacts of climate and land-cover changes in arid lands of central Asia. J. Arid Environ., 62, 285-308.

Liu, X. D., and B. D. Chen, 2000: Climatic warming in the Tibetan Plateau during recent decades. Int. J. Climatol., 20, 1729-1742.

Lorenz, E. N., 1956: Empirical orthogonal functions and statistical weather prediction. Statistical Forecast Project Rep. 1, MIT Department of Meteorology, $49 \mathrm{pp}$.

Lugina, K. M., P. Ya. Groisman, K. Ya. Vinnikov, V. V. Koknaeva, and N. A. Speranskaya, 2006: Monthly surface air temperature time series area-averaged over the 30-degree latitudinal belts of the globe, 1881-2005. A compendium of data on global change, Carbon Dioxide Information Analysis Center Rep., doi:10.3334/CDIAC/cli.003.

Ma, L., T. Zhang, Q. Li, W. Frauenfeld, and D. Qin, 2008: Evaluation of ERA-40, NCEP-1, and NCEP-2 reanalysis air temperatures with ground-based measurements in China J. Geophys. Res., 113, D15115, doi:10.1029/2007JD009549.

Mamtimin, B., A. M. M. Et-Tantawi, D. Schaefer, F. X. Meixner, and M. Domroes, 2011: Recent trends of temperature change under hot and cold desert climates: Comparing the Sahara (Libya) and central Asia (Xinjiang, China). J. Arid Environ., 75, 1105-1113.

Mann, H. B., 1945: Nonparametric tests against trend. Econometrica, 13, 245-259.

Marshall, G. J., 2002: Trends in Antarctic geopotential height and temperature: A comparison between radiosonde and NCEPNCAR reanalysis data. J. Climate, 15, 659-674.

Mayhew, B., P. Clammer, and M. Kohn, 2004: Lonely Planet Central Asia. Lonely Planet, 512 pp.

Menzel, A., 2000: Plant phenological anomalies in Germany and their relation to air temperature and NAO. Climatic Change, 57, 243-263.

_ Nature, 397, 659, doi:10.1038/17709.

— climate change matches the warming pattern. Global Change Biol., 12, 1969-1976.

Michael, T., 2011: Natural disaster risks in central Asia: A synthesis. UN Development Programme Rep., 47 pp. [Available online at http://europeandcis.undp.org/uploads/public1/ files/vulnerability/Senior \%20Economist $\% 20 \mathrm{Web} \% 20$ site/ CA_Disaster_Risks_-_MT_-_D5_11_04.pdf.] 
Mitchell, T. D., and P. D. Jones, 2005: An improved method of constructing a database of monthly climate observations and associated high-resolution grids. Int. J. Climatol., 25, 693-712.

New, M., M. Hulme, and P. Jones, 1999: Representing twentiethcentury space-time climate variability. Part I: Development of a 1961-90 mean monthly terrestrial climatology. J. Climate, 12, 829-856.

,-- , and -2000 : Representing twentieth-century spacetime climate variability. Part II: Development of 1901-96 monthly grids of terrestrial surface climate. J. Climate, 13, 2217-2238.

North, G. R., T. L. Bell, R. F. Cahalan, and F. J. Moeng, 1982: Sampling errors in the estimation of empirical orthogonal functions. Mon. Wea. Rev., 110, 699-706.

Parry, M. L., O. F. Canziani, J. P. Palutikof, P. J. van der Linden, and C. E. Hanson, Eds., 2007: Climate Change 2007: Impacts, Adaptation and Vulnerability. Cambridge University Press, 976 pp.

Pepin, N. C., and J. D. Lundquist, 2008: Temperature trends at high elevations: Patterns across the globe. Geophys. Res. Lett., 35, L14701, doi:10.1029/2008GL034026.

Pitman, A. J., and S. E. Perkins, 2009: Global and regional comparison of daily $2-\mathrm{m}$ and $1000-\mathrm{hPa}$ maximum and minimum temperatures in three global reanalyses. J. Climate, 22, 4667-4681.

Pollner, J., J. Kryspin-Watson, and S. Nieuwejaar, 2008: Disaster risk management and climate change adaptation in Europe and central Asia. The World Bank, 54 pp. [Available online at $\mathrm{http} / / /$ sistemaprotezionecivile.it/allegati/1188_DRM-Climate_ Change_Europe.pdf.]

Propastin, P. A., M. Kappas, and N. R. Muratova, 2008: Interannual changes in vegetation activities and their relationship to temperature and precipitation in central Asia from 1982 to 2003. J. Environ. Inf., 12, 75-87.

Rangwala, I., and J. Miller, 2012: Climate change in mountains: A review of elevation-dependent warming and its possible causes. Climatic Change, 114, 527-547.

Ren, G., and Coauthors, 2005: Changes of surface air temperature in China during 1951-2004 (in Chinese with English abstract). Climate Environ. Res., 10, 717-727.

—, Y. Zhou, Z. Chu, J. Zhou, A. Zhang, J. Guo, and X. Liu, 2008: Urbanization effects on observed surface air temperature trends in North China. J. Climate, 21, 1333-1348.

Rienecker, M. M., and Coauthors, 2011: MERRA: NASA's Modern-Era Retrospective Analysis for Research and Applications. J. Climate, 24, 3624-3648.

Saha, S., and Coauthors, 2010: The NCEP Climate Forecast System Reanalysis. Bull. Amer. Meteor. Soc., 91, 1015-1057.

Schiemann, R., D. Lüthi, P. L. Vidale, and C. Schär, 2008: The precipitation climate of central Asia-Intercomparison of observational and numerical data sources in a remote semiarid region. Int. J. Climatol., 28, 295-314.

Schneider, A., M. A. Friedl, and D. Potere, 2009: A new map of global urban extent from MODIS data. Environ. Res. Lett., 4, 044003, doi:10.1088/1748-9326/4/4/044003.

Shrestha, A., C. Wake, R. Mayewski, and J. Dibb, 1999: Maximum temperature trends in the Himalaya and its vicinity: An analysis based on temperature records from Nepal for the period 1971-94. J. Climate, 12, 2775-2786.

Siebert, S., P. Döll, S. Feick, J. Hoogeveen, and K. Frenken, 2007: Global map of irrigation areas, version 4.0.1. Johann Wolfgang Goethe University, Frankfurt am Main, Germany, and Food and Agriculture Organization of the United Nations, Rome, Italy. [Available online at http://www2.uni-frankfurt.de/ 45218039/Global_Irrigation_Map.]

Siegfried, T., T. Bernauer, R. Guiennet, S. Sellars, A. W. Robertson, J. Mankin, P. Bauer-Gottwein, and A. Yakovlev, 2012: Will climate change exacerbate water stress in central Asia? Climatic Change, 112, 881-899.

Simmons, A. J., and Coauthors, 2004: Comparison of trends and low-frequency variability in CRU, ERA-40, and NCEP/ NCAR analyses of surface air temperature. J. Geophys. Res., 109, D24115, doi:10.1029/2004JD005306.

Small, E. E., F. Giorgi, and L. C. Sloan, 1999: Regional climate model simulation of precipitation in central Asia: Mean and interannual variability. J. Geophys. Res., 104 (D6), 6563-6582.

Smith, T. M., and R. W. Reynolds, 2005: A global merged land and sea surface temperature reconstruction based on historical observations (1880-1997). J. Climate, 18, 2021-2036.

Solomon, S., D. Qin, M. Manning, Z. Chen, M. Marquis, K. Averyt, M. M. B. Tignor, and H. L. Miller Jr., 2007: Climate Change 2007: The Physical Science Basis. Cambridge University Press, 996 pp.

Song, H., and M. H. Zhang, 2007: Changes of the boreal winter Hadley circulation in the NCEP-NCAR and ECMWF reanalyses: A comparative study. J. Climate, 15, 5191-5200.

Sorg, A., T. Bolch, M. Stoffel, O. Solomina, and M. Beniston, 2012: Climate change impacts on glaciers and runoff in Tian Shan (central Asia). Nat. Climate Change, 2, 725-731.

Taha, H., H. Akbari, and A. Rosenfeld, 1991: Heat island and oasis effects of vegetative canopies: Micro-meteorological fieldmeasurements. Theor. Appl. Climatol., 44, 123-138.

Trenberth, K. E., and Coauthors, 2007: Observations: Surface and atmospheric climate change. Climate Change 2007: The Physical Science Basis, S. Solomon et al., Eds., Cambridge University Press, 235-336.

UNDP, 2005: Central Asia human development report. UN Development Programme, $246 \mathrm{pp}$.

Vuille, M., and R. S. Bradley, 2000: Mean annual temperature trends and their vertical structure in the tropical Andes. Geophys. Res. Lett., 27, 3885-3888.

- _ - M. Werner, and F. Keimig, 2003: 20th century climate change in the tropical Andes: Observations and model results. Climatic Change, 59, 75-99.

Wang, S. W., and D. Y. Gong, 2000: Enhancement of the warming trend in China. Geophys. Res. Lett., 27, 2581-2584.

You, Q. L., S. C. Kang, N. Pepin, W. A. Flugel, Y. P. Yan, H. Behrawan, and J. Huang, 2010: Relationship between temperature trend magnitude, elevation and mean temperature in the Tibetan Plateau from homogenized surface stations and reanalysis data. Global Planet. Change, 71, 124-133.

Zhang, Q., and M. Zhao, 1999: Field experiment and numerical simulation of inverse over humidity of atmosphere over desert oasis (in Chinese). Acta Meteor. Sin., 57, 729-740.

Zhou, L., R. E. Dickinson, Y. Tian, J. Fang, Q. Li, R. Kaufmann, C. Tucker, and R. B. Myneni, 2004: Evidence for a significant urbanization effect on climate in China. Proc. Natl. Acad. Sci. USA, 101, 9540-9544.

Zoi Environment Network, 2009: Climate change in central Asia: A visual synthesis. Zoï environment publication, $79 \mathrm{pp}$. [Available online at http://www.preventionweb.net/english/ professional/publications/v.php?id=12033.] 